IZA DP No. 8993

Fiscal Policy, Interest Rate Spreads, and the Zero Lower Bound

Christian Bredemeier

Falko Juessen

Andreas Schabert

April 2015 


\title{
Fiscal Policy, Interest Rate Spreads, and the Zero Lower Bound
}

\author{
Christian Bredemeier \\ University of Cologne \\ Falko Juessen \\ University of Wuppertal \\ and IZA \\ Andreas Schabert \\ University of Cologne
}

Discussion Paper No. 8993

April 2015

IZA
P.O. Box 7240
53072 Bonn
Germany

Phone: +49-228-3894-0

Fax: +49-228-3894-180

E-mail: iza@iza.org

\begin{abstract}
Any opinions expressed here are those of the author(s) and not those of IZA. Research published in this series may include views on policy, but the institute itself takes no institutional policy positions. The IZA research network is committed to the IZA Guiding Principles of Research Integrity.

The Institute for the Study of Labor (IZA) in Bonn is a local and virtual international research center and a place of communication between science, politics and business. IZA is an independent nonprofit organization supported by Deutsche Post Foundation. The center is associated with the University of Bonn and offers a stimulating research environment through its international network, workshops and conferences, data service, project support, research visits and doctoral program. IZA engages in (i) original and internationally competitive research in all fields of labor economics, (ii) development of policy concepts, and (iii) dissemination of research results and concepts to the interested public.
\end{abstract}

IZA Discussion Papers often represent preliminary work and are circulated to encourage discussion. Citation of such a paper should account for its provisional character. A revised version may be available directly from the author. 
IZA Discussion Paper No. 8993

April 2015

\section{ABSTRACT}

\section{Fiscal Policy, Interest Rate Spreads, and the Zero Lower Bound}

This paper questions unconventional fiscal policy effects when the monetary policy rate is at the zero lower bound. We provide evidence for the US that the spread between the policy rate and the US-LIBOR, which is more relevant for private sector transactions, increases with government expenditures. We introduce a corresponding spread into an otherwise standard macroeconomic model which reproduces this observation. The model predicts that the fiscal multiplier takes conventional values, regardless of whether the policy rate follows a standard feedback rule or is at its zero lower bound. Likewise, labor tax increases exert contractionary effects in both cases.

JEL Classification: E32, E42, E63

Keywords: fiscal multiplier, tax policy, interest rate spreads, zero lower bound, liquidity premium

Corresponding author:

Andreas Schabert

University of Cologne

Center for Macroeconomic Research

Albertus-Magnus-Platz

50923 Cologne

Germany

E-mail: schabert@wiso.uni-koeln.de

Financial support from the Deutsche Forschungsgemeinschaft (SPP 1578) is gratefully acknowledged. 


\section{Introduction}

Are fiscal policy effects exceptional at the zero lower bound? This question has received broad attention as the recent financial crisis has led central banks to lower interest rates and governments to spend large amounts of money for fiscal stimulus programs. According to the neoclassical view on fiscal policy (see Barro, 1981, or Baxter and King, 1993), government spending exerts a positive effect on output and crowds-out private absorption, while alternative theoretical approaches have been able to generate a crowding in (see e.g. Galí et al., 2007). For the particular case where the central bank sets the short-run nominal interest rate at its zero lower bound (ZLB), Christiano et al. (2011) and Eggertsson (2011) have shown that fiscal multipliers can become extremely large and that labor income tax cuts can be contractionary. ${ }^{1}$ Yet, there is only little applicable evidence on fiscal multipliers at the ZLB available and it suggests that they are not higher than on average (see Canova and Pappa, 2011, Crafts and Mills, 2013, Ramey and Zubairy, 2014, and Dupor and Li, 2014). Recently, also some theoretical studies have raised doubts about large fiscal multipliers at the ZLB. Specifically, Drautzburg and Uhlig (2013) find a multiplier at the ZLB of roughly one half mainly due to effects of future distortionary taxation, Mertens and Ravn (2014) show that due to multiple equilibria at the ZLB the multiplier might even be smaller than under normal circumstances, and Cochrane (2015) shows that under a given path of interest rate expectations alternative solutions of the New Keynesian model can even be associated with negative fiscal multipliers. ${ }^{2}$

In this paper, we focus on a different and fairly obvious aspect that questions the existence of unconventional fiscal policy effects when the monetary policy rate is held at the ZLB, namely, that the ZLB is less relevant for interest rates that are not set by the central bank. The main reason for large fiscal multipliers in the above cited studies is that nominal rates of return that relate to private agents' intertemporal choices are fixed, i.e. that the (nominal) marginal rate of intertemporal substitution is bound at zero, such that inflationary events and policies tend to stimulate private consumption by reducing the real interest rate. Empirically, however, the US monetary policy rate, i.e. the federal funds rate, applies to a relatively small volume of overnight money market transactions, whereas other interest rates can well be above zero even if the policy rate is at the ZLB. ${ }^{3}$ A key observation for our analysis is that

\footnotetext{
${ }^{1}$ Similar results regarding the fiscal multiplier can be found in Woodford (2011) and Fahri and Werning (2013), while Fernandez-Villaverde et al. (2012), Carlstrom et al. (2014), and Erceg and Linde (2014) qualify these results.

${ }^{2}$ Furthermore, Wieland (2014) provides evidence for adverse effects of negative supply shocks at the ZLB and provides a consistent New Keynesian model augmented by borrowing-constrained households, which implies fiscal multipliers at the ZLB of less than one. Kiley (2014) shows, among other results, that fiscal multipliers at the ZLB are smaller than one when the assumption of price stickiness is replaced by sticky information. Bilbiie et al. (2014) focus on welfare implications and show that non-utility providing government spending is welfare-detrimental at the ZLB.

${ }^{3}$ This argument has also been made by Ohanian (2011) in the context of fiscal multipliers at the ZLB.
} 
interest rates which are more relevant for private sector transactions, as for example the US-LIBOR, in general exceed the federal funds rate, including the time when the recent US fiscal stimulus program (ARRA) has been implemented. Yet, a positive spread would be negligible for the analysis of the fiscal multiplier if it were constant or at least invariant to changes in fiscal policy. To unveil whether the spread reacts to fiscal policy, we estimate fiscal VARs using US data. As our main novel empirical contribution, we find that the spread between the 3-month US-LIBOR (which is the interest rate that corresponds most closely to the theoretical counterpart in our model) and the federal funds rate increases in response to expansionary government expenditure shocks under different identification schemes. Taken together, this evidence suggests that the transmission of government spending shocks might not be qualitatively affected by the central bank holding the policy rate at the ZLB, given that this does not rule-out (upward) adjustments in interest rates that are more relevant for private sector transactions.

We then apply a framework, which builds on a standard New Keynesian model and reproduces these empirical findings, to re-examine the role of monetary policy and, in particular, the ZLB for fiscal policy effects. Specifically, the interest rate on illiquid assets, which equals the nominal marginal rate of intertemporal substitution in our model, will exceed the monetary policy rate. In contrast to standard New Keynesian models, the nominal marginal rate of intertemporal substitution is therefore not directly controlled by the central bank. Following Schabert (2015), this property is modelled by accounting for the fact that central banks typically supply reserves to commercial banks against eligible assets, i.e. treasury bills, in open market operations. While the short-term treasury rate closely follows the policy rate, the interest rate on non-eligible assets tends to be higher due to a liquidity premium on eligible assets. ${ }^{4}$ The nominal marginal rate of intertemporal substitution then evolves endogenously, reflecting the dynamics of consumption and inflation, regardless of whether the policy rate is fixed or not. To facilitate comparisons with related studies, we further account for standard features of the model, like sticky prices, capital accumulation, and consumption habits (as in Christiano et al., 2011), such that the model only differs from standard models by the endogenous liquidity premium. ${ }^{5}$

For a simplified version of the model, we show analytically how fiscal policy affects interest rates and real activity. As the main novel theoretical result, we show that the model predicts that government spending and increases of the labor income tax rate exert conventional effects regardless of whether the policy rate is set according to a standard feedback rule or is fixed. Specifically, the model supports the neoclassical view on fiscal policy, as government spending

\footnotetext{
${ }^{4}$ Andolfatto and Williamson (2015) provide a monetary policy analysis at the ZLB in a New Monetarist model where the treasury rate (set by the central bank) exhibits a liquidity premium.

${ }^{5}$ While we consider banks in order to motivate demand for reserves and to identify an interest rate on interbank loans, we neglect financial frictions such that the Modigliani-Miller theorem applies.
} 
increases output due to a wealth effect and crowds-out private absorption (see Linnemann and Schabert, 2003 or Woodford, 2011). As consumption growth and inflation respond positively to an increase in government spending, the nominal marginal rate of intertemporal substitution and its spread relative to the policy rate increase as well, consistent with our VAR evidence. These results are further confirmed numerically by applying a calibrated version of the model and for a scenario where an adverse shock drives the policy rate temporarily to the ZLB. At the ZLB, fiscal multipliers further do not decrease with the degree of price stickiness, which has, for example, been stressed by Cochrane (2015) as a puzzling property at the ZLB. Moreover, we find that effects of an increase in the labor income tax rate are not reversed when the policy rate is at the ZLB, which differs from Eggertsson's (2011) paradox of toil. The analysis thus indicates that fiscal policy effects are not substantially altered when the central bank sets the monetary policy rate at its zero lower bound, as long as interest rates that are more relevant for private sector transactions differ from the monetary policy rate.

Section 2 provides empirical evidence. Section 3 presents the model. In Section 4, we derive analytical results on fiscal policy effects for a simplified version. The Section further presents impulse responses for a calibrated version of the model and for a scenario where an adverse shock drives the policy rate temporarily to the ZLB. Section 5 concludes.

\section{Empirical evidence}

In this Section, we examine fiscal policy effects on the spread between the monetary policy rate, i.e. the federal funds rate, and an interest rate that is typically more relevant for private sector transactions. We thus provide evidence for a mechanism that reconciles theory with empirical findings (see for example Ramey and Zubairy, 2014), rather than presenting further evidence on the fiscal multiplier at the ZLB.

The (effective) federal funds rate is the overnight rate that banks charge when borrowing and lending federal funds, which are deposited at the central bank, among each other. Our analysis builds on the fact that the federal funds rate is only relevant for a small volume of transactions, while other money market rates in subsequent stages of the monetary transmission process are more relevant for private sector borrowing and serve as benchmarks for financial markets. Specifically, we consider the US-LIBOR, which is a money market rate at which banks freely borrow and lend among each other and which is commonly viewed as the most important short-term interest rate (see e.g. IMF, 2012). The three-month US-LIBOR, which corresponds most closely to the theoretical counterpart in our model, usually exceeds the federal funds rate systematically. For example, during the period 1986.I-2013.II, which is the sample period for our baseline analysis (see below), it averages 28 basis points above the federal funds rate. Excluding the recent financial crisis, the mean spread is 25 basis points 
(period 1986.I-2008.II). Notably, the US-LIBOR has also been above the federal funds rate during the recent US fiscal stimulus program of the American Recovery and Reinvestment Act (ARRA), see Figure 10 in Appendix A. Thus, the three-month US-LIBOR is relatively close to the monetary policy rate, but even at times where the latter has broadly been perceived as being at the zero lower bound, there was a positive spread between the two interest rates. Longer-term interest rates or non-money market rates are evidently characterized by larger (term or risk) premia and are typically associated with larger spreads relative to the federal funds rate. Hence, the numbers above can be viewed as a conservative estimate of differences between the monetary policy rate and interest rates that are more relevant for private sector transactions.

The mere existence of a positive interest rate spread might however not question the adequacy of analyzing fiscal policy effects with single interest rate models. If, for example, the spread between the US-LIBOR and the federal funds rate were roughly constant, one could argue that it hardly matters for economic analysis, justifying the assumption that both rates behave approximately identically. For this reason, we investigate whether these interest rates respond differently to changes in government spending. Our results will show that the money market spread, i.e. the spread between the three-month US-LIBOR and the federal funds rate, moves endogenously with macroeconomic aggregates and, in particular, varies with fiscal policy measures. This finding suggests that interest rate responses are potentially important for the analysis of fiscal policy effects. In particular, when the policy rate is at the zero lower bound, assuming that the rates behaved identically would lead to mistaking also other interest rates as constant.

To show that the money market spread is characterized by a systematic and therefore non-negligible association with the stance of fiscal policy, we investigate how it responds in the short-run to fiscal policy shocks by applying fiscal VARs. In our baseline specification, we identify fiscal policy shocks recursively following Blanchard and Perrotti (2002), while we further report results for two alternative VAR identification schemes. We estimate a parsimonious VAR using quarterly data on government spending, GDP, a measure of private absorption (private consumption and investment), and include the money market spread as an additional variable. ${ }^{6}$ The sample period is 1986.I-2013.II, where the beginning of the sample period is restricted by the data availability for the US-LIBOR. Except for the money market spread, all variables are in real per capita terms and in logs. We include a linear-quadratic time trend and account for four lags.

Figure 1 shows the impulse response functions from the estimated baseline VAR with government spending ordered first. The shaded areas show $68 \%$ bootstrapped confidence

\footnotetext{
${ }^{6}$ Details on data sources and variable definitions for the baseline VAR and the alternative specifications can be found in Appendix A.
} 

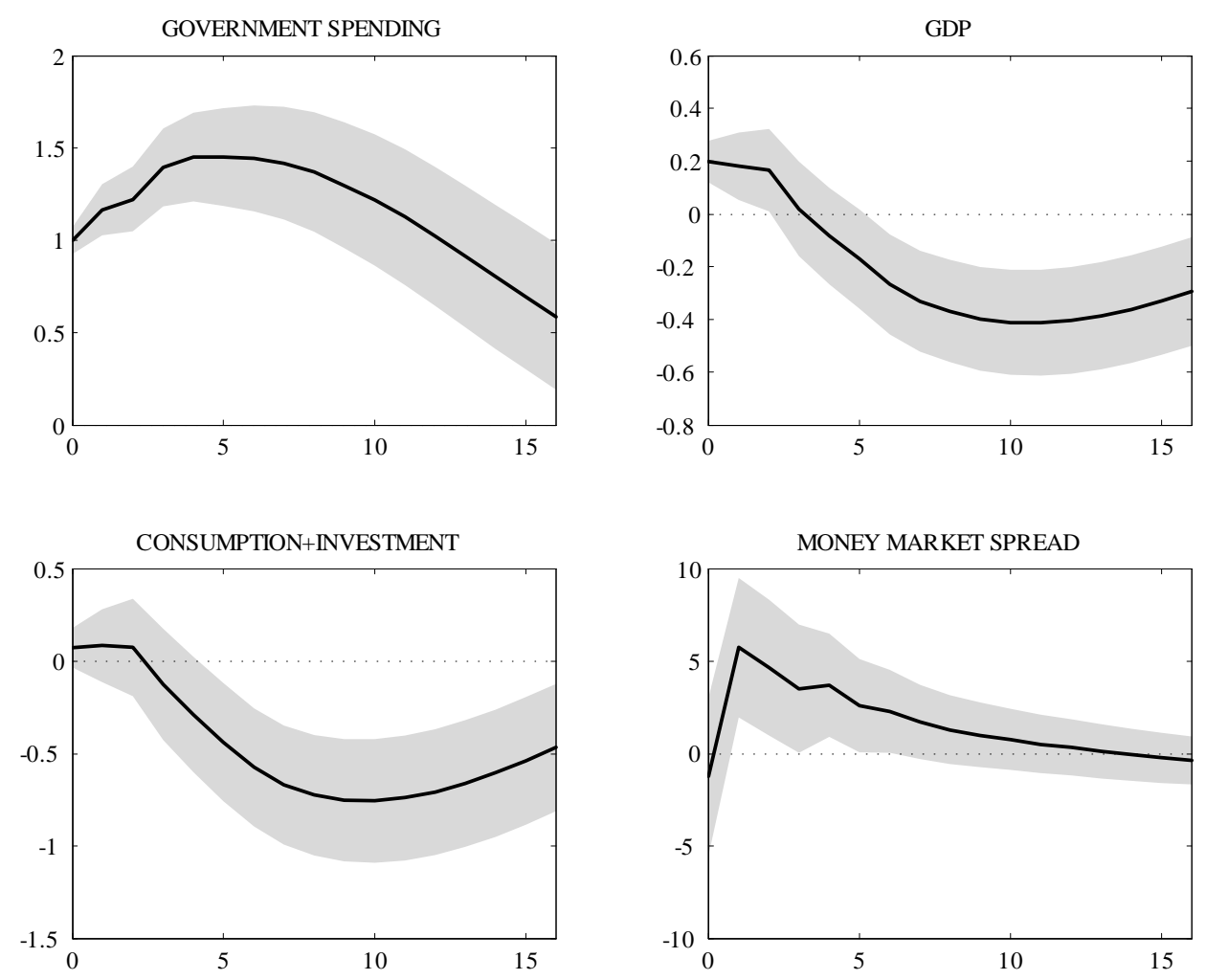

Figure 1: Responses to a government-spending shock, identification: Blanchard and Perrotti (2002), sample: 1986.I-2013.II.

intervals. The impact fiscal multiplier is estimated to be close to one ${ }^{7}$ while the expansionary effect of government spending is relatively short-lived, in line with the results of Perotti (2005) for a post-1980 sample. We further find that private absorption is significantly crowded-out. ${ }^{8}$ As the main novel empirical finding, we observe that the money market spread increases significantly in response to a fiscal stimulus. Quantitatively, a one percent increase in government spending leads to a median peak response of the spread of 5.7 b.p. These results are qualitatively robust to the exclusion of the recent financial crisis episode, as can be seen from Figure 11 in Appendix A.

We further examine whether the response of the money market spread is robust to a change in the identification strategy of fiscal shocks, applying two alternative fiscal VARs. First, we follow Pappa (2009) and use sign restrictions to identify fiscal shocks. We estimate a VAR using GDP, the primary deficit, government spending, and the money market spread.

\footnotetext{
${ }^{7}$ On impact, a one percent increase in government spending leads to a 0.199 percent (mean) increase in GDP. With an average share of government spending over GDP of $19.6 \%$ in our sample, the fiscal multiplier on impact is $0.199 / 0.196=1.015$.

${ }^{8}$ For the sample 1947.I-2008.III, Ramey (2011) finds an insignificant response of consumption and a significant crowding out of investment when using the Blanchard-Perotti identification.
} 

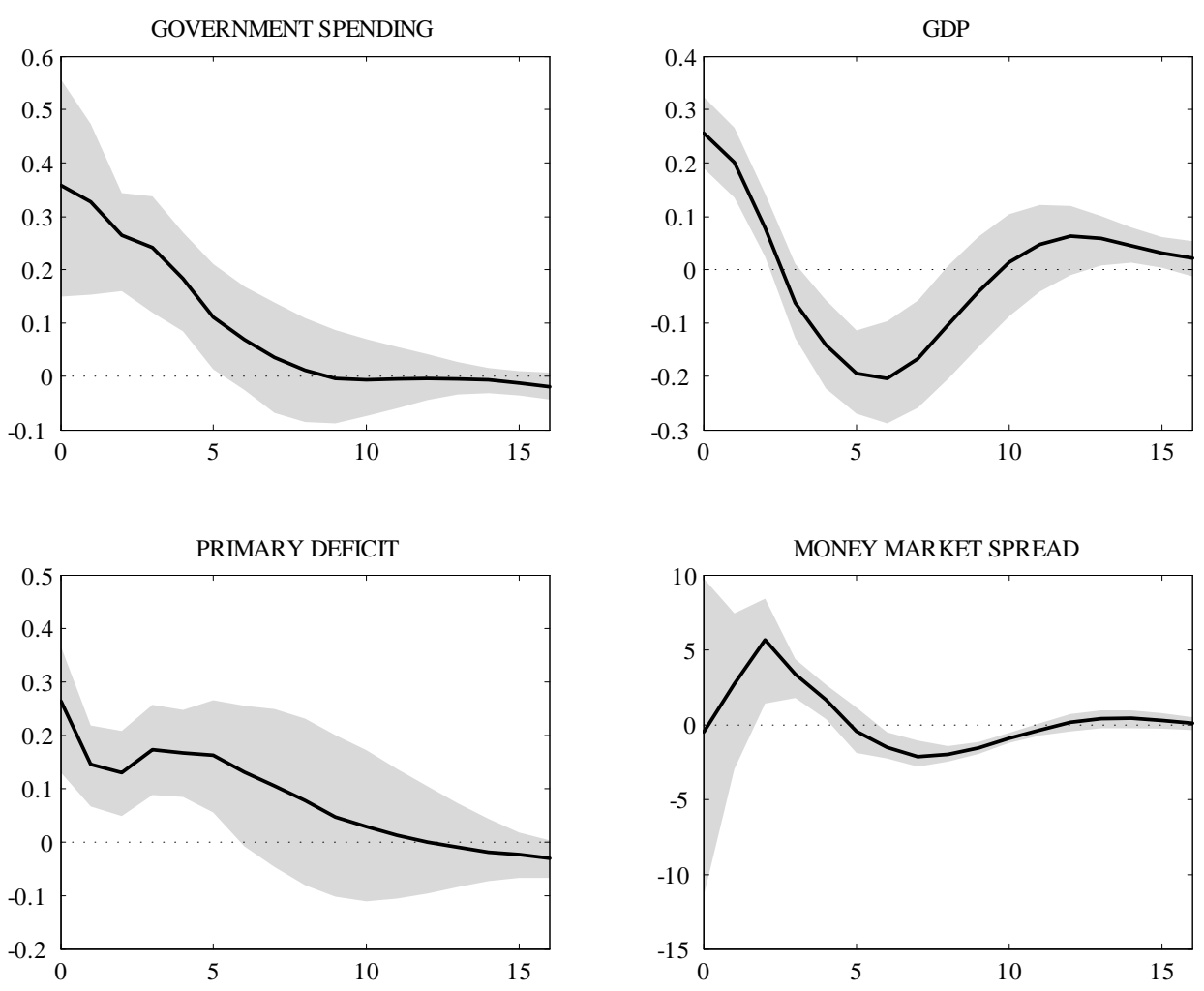

Figure 2: Responses to a fiscal-policy shock, identification: Pappa (2009), sample: 1986.I2013.II.

Following Pappa (2009), fiscal shocks are identified by an impact increase in the primary fiscal deficit and in GDP, respectively, while being orthogonal to non-fiscal shocks that move GDP and the primary deficit in opposite directions. As Canova and Pappa (2011), we impose as an additional restriction that fiscal shocks raise government spending. The sample period is again 1986.I-2013.II. and we account for four lags. In line with Mountford and Uhlig (2009), who also apply sign restrictions to identify fiscal shocks, the increase in GDP is found to be short-lived, as can be seen from Figure 2. The relative changes of GDP, spending, and the deficit are very similar to the ones reported by Enders et al. (2011). Since GDP rises by about the same amount as the deficit, on impact the fiscal multiplier is close to one also in this specification. ${ }^{9}$ Most importantly, also for the identification based on sign restrictions, we find that the money market spread increases significantly in response to fiscal expansions. ${ }^{10}$

We consider a second alternative identification strategy to address Ramey's (2011) antic-

\footnotetext{
${ }^{9}$ The fiscal shocks considered here also include tax cuts such that the increase in the deficit is the most appropriate measure to quantify the size of the fiscal impulse. A fiscal shock raises the deficit by $0.27 \%$ of mean GDP and GDP by $0.26 \%$ of mean GDP such that the multiplier is $0.26 / 0.27=0.96$.

${ }^{10}$ Notably, the effects of the fiscal shock on the spread is of similar magnitude as in our baseline VAR. The same holds for the next identification scheme.
} 

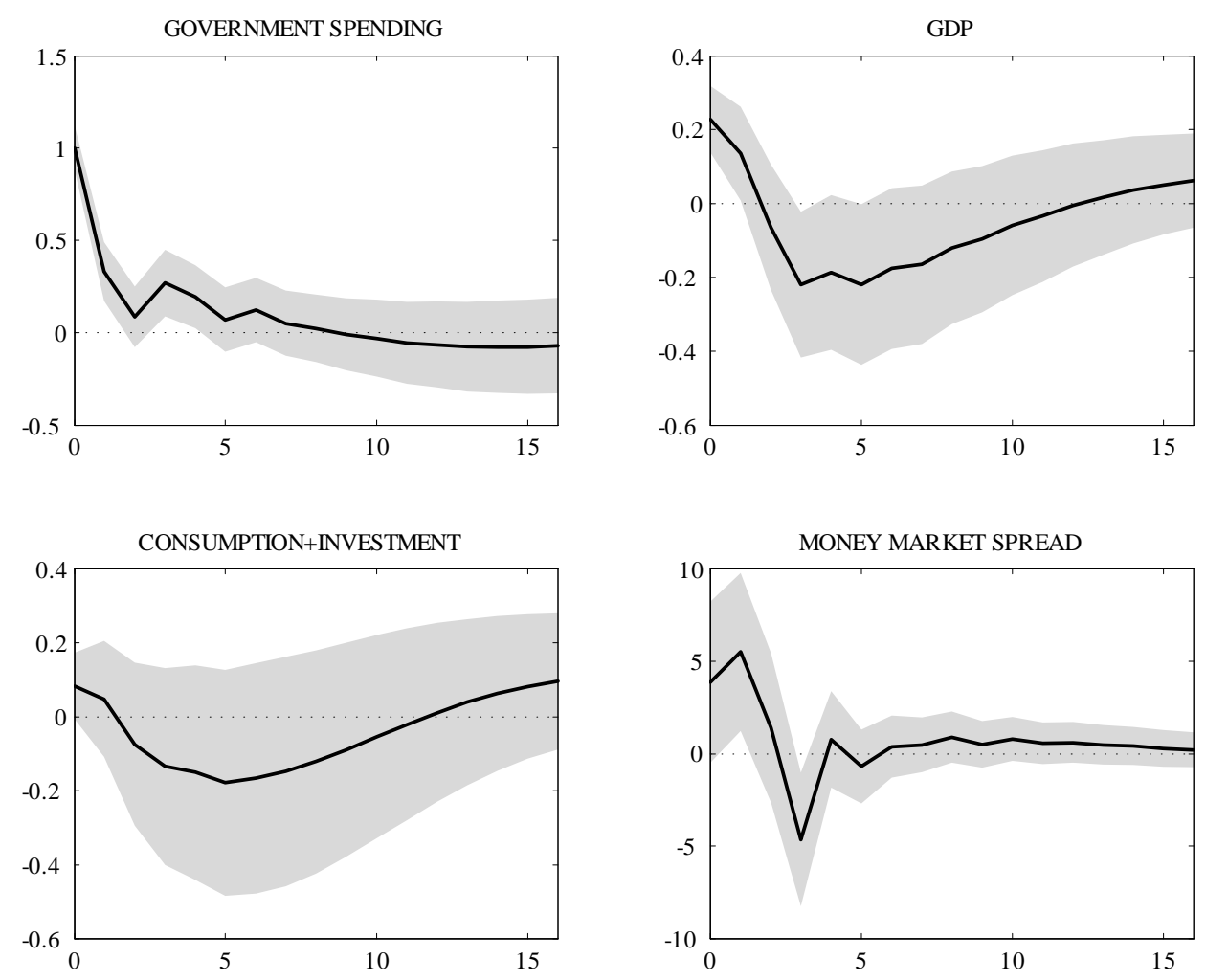

Figure 3: Responses to a government-spending shock, identification: forecast errors based on survey of professional forecasters, sample: 1969.I-2008.II.

ipation critique of the simple recursive identification approach. Specifically, we use Ramey's (2011) preferred identification for the post-Korean war sample period using news shocks based on professional forecasts. The professional forecasts are taken directly from Ramey (2011) and are available until 2008. The sample period for this specification is 1986.I-2008.II and we account for three lags. The VAR includes the forecast error ordered first, government spending, GDP, private absorption, and the money market spread as an additional variable. Figure 3 shows the impulse responses to an unanticipated shock to government spending. ${ }^{11}$ As for the previous identification schemes, we find that the money market spread increases significantly in response to an unanticipated shock to government spending. In line with our previous estimates, we find the expansionary effects of fiscal shocks to be short-lived. The estimates are very similar to Ramey's (2011) post-Korean war estimates, where she also finds that GDP rises slightly on impact, but the response then turns negative. In Ramey (2011), this is accompanied by a crowding out of consumption and investment, similar to what we find for our measure of private absorption.

\footnotetext{
${ }^{11}$ The response of the forecast error is not shown for convenience.
} 
Overall, the VAR evidence shows that the specific form of the responses to government spending shocks varies across identifications but we found a remarkably robust result with respect to the money market spread. ${ }^{12}$ In fact, the response of the money market spread to government spending shocks is positive under all three identifications schemes. Based on this evidence, it can be expected that the way the monetary policy rate is set by the central bank is less important for the transmission of fiscal policy shocks than predicted by models with a single nominal interest rate. In particular, our empirical findings suggest that the fiscal multiplier might not be substantially altered when the policy rate is fixed at the ZLB, given that interest rates that are more relevant for private sector transactions are positive and tend to adjust upwards after fiscal shocks. In the following, we develop a model that is able to replicate these findings, which we then use to analyze fiscal policy effects for policy rates above and at the ZLB.

\section{The model}

In this Section, we develop a macroeconomic model for the analysis of fiscal policy effects. We pay particular attention to the possibility that the monetary policy rate might differ from nominal rates of return on assets issued by private agents. To explain these differences, we consider commercial banks that demand high powered money, i.e. reserves supplied by the central bank via open market operations. Banks further offer demand deposits to households, who rely on (broad) money for goods market transactions, and serve as intermediaries between households and firms (by, say, providing convenience of denomination). As in Schabert (2015), we account for the fact that reserves are only supplied against eligible assets, i.e. treasury securities. Interest rates on non-eligible assets and on loans charged between private agents will therefore exceed the monetary policy rate (as well as the treasury rate) by a liquidity premium on eligible assets. To isolate the main mechanism, we neither model frictions that justify the existence of banks nor other financial market frictions. The model further contains standard features of macroeconomic models (e.g. sticky prices, endogenous capital accumulation, and habit persistence), which are not essential for our main results, but are included to facilitate comparisons with related studies on fiscal multipliers (as for example Christiano et al., 2011). Thus, the model is constructed to feature only a single non-standard element, i.e. the endogenous liquidity premium, which accords to the money market spread investigated in Section 2.

In each period, the timing of events in the economy, which consists of households, banks, intermediate goods producing firms, and retailers, unfolds as follows: ${ }^{13}$ At the beginning of

\footnotetext{
${ }^{12}$ Caldara and Kamps (2008), who compare different identification strategies (including the three applied here) for a five-variable VAR, also find that impact multipliers differ across specifications and vary between close to zero and one.

${ }^{13}$ Further details on the timing of events and the flow of funds can be found in Schabert (2015).
} 
each period, aggregate shocks materialize. Then, banks can acquire reserves from the central bank via open market operations. Subsequently, the labor market opens, goods are produced, and the goods market opens, where money is used by households as a means of payment. At the end of each period, the asset market opens and investment/borrowing decisions are made. Throughout the paper, upper case letters denote nominal variables and lower case letters real variables.

\subsection{Households}

There is a continuum of infinitely lived and identical households of mass one. The representative household enters a period $t$ with holdings of bank deposits $D_{t-1} \geq 0$ and shares of firms $z_{t-1} \in[0,1]$ valued at the price $V_{t}$. It maximizes the expected sum of a discounted stream of instantaneous utilities $u_{t}$ :

$$
E_{0} \sum_{t=0}^{\infty} \beta^{t} \xi_{t} u_{t}
$$

where $E_{0}$ is the expectation operator conditional on the time 0 information set, and $\beta \in(0,1)$ is the subjective discount factor. The instantaneous utility function is given by $u\left(c_{t}, \bar{c}_{t-1}, n_{t}\right)=\Upsilon\left[\left(c_{t}-h \bar{c}_{t-1}\right)^{1-\sigma} /(1-\sigma)\right]-\theta n_{t}^{1+\sigma_{n}} /\left(1+\sigma_{n}\right)$, where $\sigma \geq 1, \sigma_{n} \geq 0$, $\theta, \Upsilon=1$, and $h \geq 0$, and $\bar{c}_{t}$ indicates external habit formation. The term $\xi_{t}$ is a preference shock satisfying $\log \xi_{t}=\rho_{\xi} \log \xi_{t-1}+\varepsilon_{\xi, t}$, where $\varepsilon_{\xi, t}$ is i.i.d. with zero mean and $\rho_{\xi} \in[0,1)$. This shock is introduced solely to drive the policy rate to the ZLB (as e.g. in Eggertsson, 2011).

Households can store their wealth in shares of firms $z_{t} \in[0,1]$ valued at the price $V_{t}$ with the initial endowment $z_{-1}$. We assume that households rely on cash for purchases of consumption goods, while we abstract from purchases of goods via credit, for convenience. For this, households can in principle hold cash, which is dominated by the rate of return of other assets. Instead, we consider demand deposits that are offered by banks (see below) and that are assumed to serve the same purpose. Households typically hold more deposits than necessary for consumption expenditures such that the goods market constraint, which corresponds to a standard cash in advance constraint, can be summarized as

$$
P_{t} c_{t} \leq \mu D_{t-1},
$$

where $\mu \in[0,1]$ denotes an exogenous fraction of deposits withdrawn by the representative household. The goods market constraint (2) can be motivated as follows: Suppose that ex-ante identical households receive idiosyncratic preference shocks with bounded support that shift their valuation of consumption (say, $\Upsilon_{j}$ for a household $j$ ) and that are realized in each period before the goods market opens. A constrained efficient allocation can be implemented if households with a higher consumption valuation were endowed with more money. However, when households decide on their money holdings in period $t-1$, their 
decision refers to an expected (mean) consumption level in the next period, which implies an inefficient consumption allocation in period $t$ (given that there is no beginning-of-period inter-household money market). Now suppose that banks offer demand deposits, which might earn a positive interest rate and can be withdrawn within each period. A Pareto-superior allocation can then be implemented when all households hold deposits that are just as large as to finance consumption for the maximum valuation (induced by the preference shock). Households with a lower valuation of consumption will then withdraw not all deposits for consumption expenditures, such that $\mu$ represents a mean fraction of withdrawn deposits (which actually depends on the distribution of the preference shocks). ${ }^{14}$

Hence, we neglect cash holdings of households as well as their holdings of treasury bills, which will be held by banks to satisfy the liquidity requirement. ${ }^{15}$ We assume that banks offer demand deposits at the period $t$ price $1 / R_{t}^{D}$, which lead to a payoff of one unit in period $t+1$. The budget constraint of the household is given by

$$
\left(D_{t} / R_{t}^{D}\right)+V_{t} z_{t}+P_{t} c_{t}+P_{t} \tau_{t} \leq D_{t-1}+\left(V_{t}+P_{t} \varrho_{t}\right) z_{t-1}+\left(1-\tau_{t}^{n}\right) P_{t} w_{t} n_{t}+P_{t} \varphi_{t},
$$

where $\tau_{t}$ denotes a lump-sum tax, $\varrho_{t}$ dividends from intermediate goods producing firms, $\tau_{t}^{n}$ a labor income tax, $w_{t}$ the real wage rate, $n_{t}$ working time, and $\varphi_{t}$ profits from banks and retailers. Maximizing the objective (1) subject to the goods market constraint (2), the budget constraint (3), and the borrowing constraints $D_{t} \geq 0$ and $z_{t} \geq 0$ for given initial values leads to the following first order conditions for working time, consumption, shares, and deposits:

$$
\begin{aligned}
\xi_{t}\left(-u_{n, t}\right) /\left[\left(1-\tau_{t}^{n}\right) w_{t}\right] & =\lambda_{t}, \\
\xi_{t} u_{c, t} & =\lambda_{t}+\psi_{t}, \\
\beta E_{t}\left[\lambda_{t+1} R_{t+1}^{q} \pi_{t+1}^{-1}\right] & =\lambda_{t}, \\
\beta E_{t}\left[\left(\lambda_{t+1}+\mu \psi_{t+1}\right) \pi_{t+1}^{-1}\right] & =\lambda_{t} / R_{t}^{D},
\end{aligned}
$$

where $u_{n, t}=\partial u_{t} / \partial n_{t}$ and $u_{c, t}=\partial u_{t} / \partial c_{t}$ denote marginal (dis-)utility from labor and consumption, $R_{t}^{q}=\left(V_{t}+P_{t} \varrho_{t}\right) / V_{t-1}$ is the nominal rate of return on equity, and $\psi_{t}$ and $\lambda_{t}$ denote the multipliers on the goods market constraint (2) and the asset market constraint (3). Finally, the following complementary slackness conditions hold in the household's opti-

\footnotetext{
${ }^{14}$ To be more specific, suppose that ex-ante identical households $j \in[0,1]$ draw i.i.d. consumption preference shocks $\Upsilon_{j} \in\left\{\ldots, \Upsilon_{\text {low }}, \ldots, \Upsilon_{\text {high }}, \ldots, \Upsilon_{\max }\right\}$ after money and asset markets are closed. A constrained efficient allocation (under positive opportunity costs of money) would for $h=0$ imply $\Upsilon_{\text {high }} \widetilde{c}_{\text {high,t }}^{-\sigma}=\Upsilon_{\text {low }} \widetilde{c}_{\text {low }, t}^{-\sigma}$ and thus $\widetilde{c}_{\text {high }, t}>\widetilde{c}_{\text {low }, \text { for }} \Upsilon_{\text {high }}>\Upsilon_{\text {low }}$. When banks offer demand deposits, this allocation can be implemented when all households invest in deposits satisfying $D_{t-1}=P_{t} \widetilde{c}_{\max , t}$ such that those households with $\Upsilon_{\max }$ withdraw all deposits and those with $\Upsilon_{j, t}<\Upsilon_{\max }$ withdraw less. Defining $\mu_{j}$ as individual fractions of withdrawn deposits and aggregating over liquidity constraints would then lead to $\int P_{t} c_{j, t} d j \leq$ $\left(\int \mu_{j} d j\right) D_{\max , t-1}$, which can be rewritten as $P_{t} c_{t} \leq \mu D_{t-1}$, where $c_{t}=\int c_{j, t} d j, \mu=\sum \mu_{j}$, and $D_{t-1}=$ $D_{\max , t-1}$.

${ }^{15}$ In equilibrium, fiat money and treasury bills will be dominated in rate of return by household assets.
} 
mum, $0 \leq \mu d_{t-1} \pi_{t}^{-1}-c_{t}, \psi_{t} \geq 0, \psi_{t}\left(\mu d_{t-1} \pi_{t}^{-1}-c_{t}\right)=0$, where $d_{t}=D_{t} / P_{t}$, as well as (3) with equality and the associated transversality conditions. Under a binding goods market constraint (2), $\psi_{t}>0$, the deposit rate tends to be lower than the expected return on equity (see 6 and 7 ), as demand deposits provide transaction services.

\subsection{Banks}

As mentioned above, banks receive demand deposits from households, supply loans to firms, and hold treasury bills and reserves for liquidity needs. The banking sector is modelled as simple as possible, while accounting - arguably in a stylized way - for the way the US Federal Reserve implements monetary policy: In the recent past (before the financial crisis), the Fed has announced a target for the federal funds rate, i.e. the interest rate at which depository institutions lend reserve balances to other depository institutions overnight. Reserves are originally issued by the central bank via open market operations, which determine the overall amount of available federal funds that are distributed over the banking sector via the federal funds market. Due to federal funds' unique ability to be used to satisfy reserve requirements, banks rely on federal funds market transactions when their reserves demand within a maintenance period is not directly met by central bank open market transactions. These open market operations are either carried out as outright transactions or as repurchase agreements, i.e. as permanent or temporary sales/purchases of eligible securities, between the central bank and primary dealers (i.e. banks or broker-dealers). Outright transactions are conducted to accommodate trend growth of currency in circulation, while repurchase agreements are conducted by the Fed to fine-tune the supply of reserves such that the effective federal funds rate meets its target value.

In the short run, banks thus have access to reserves via temporary open market transactions with the central bank or via overnight transactions in the federal funds market. This implies that rates charged for both types of transactions should be similar. Although borrowing from the central bank (via repos) differs from borrowing via the federal funds market, as e.g. interbank loans are unsecured, the rates/costs at which banks can acquire reserves are actually almost identical (since overnight loans are hardly associated with counterparty risks). This can be seen from Figure 12 in Appendix D, which shows the effective federal funds rate and the rate on Federal Reserve treasury repurchase agreements for January 2005 (where the availability of data on repo rates starts) to June 2014. The figure discloses that differences between the effective federal funds rate and the rate on treasury repurchase agreements were negligible (four b.p. on average) before the financial crisis, in particular, when these rates are compared to interest rates on bank deposit liabilities (e.g. the US-LIBOR, see Figure 10 in Appendix D). ${ }^{16}$ This point has also been emphasized by, e.g., Bech et al. (2012). To

\footnotetext{
${ }^{16}$ Given that many US financial instruments are actually based on the US-LIBOR rate rather than on the
} 
account for this observation in our macroeconomic model, we assume that the federal funds rate is identical to the repo rate in open market operations, while we endogenously derive a spread between these rates (including the treasury bill rate) and interest rates on other assets/liabilities that originates in a liquidity premium. ${ }^{17}$

For the model, we consider a continuum of perfectly competitive banks $i \in[0,1]$. A bank $i$ receives demand deposits $D_{i, t}$ from households and supplies risk-free loans to firms $L_{i, t}$ at the price $1 / R_{t}^{L}$. Bank $i$ further holds short-term government debt (i.e. treasury bills) $B_{i, t-1}$ and reserves $M_{i, t-1}$ for withdrawals of deposits by households. As in Schabert (2015), the central bank supplies reserves via open market operations either outright or temporarily under repurchase agreements; the latter corresponding to a collateralized overnight loan offered by the central bank. In both cases, treasury bills serve as collateral for central bank money, while the price of reserves in open market operations in terms of treasuries (the repo rate) equals $R_{t}^{m}$. Specifically, reserves are supplied by the central bank only in exchange for treasuries $\Delta B_{i, t}^{C}$, while the price of money is the repo rate $R_{t}^{m}$ :

$$
I_{i, t}=\Delta B_{i, t}^{C} / R_{t}^{m} \quad \text { and } \quad \Delta B_{i, t}^{C} \leq B_{i, t-1},
$$

where $I_{i, t}$ denotes additional money received from the central bank. Hence, (8) describes a central bank money supply constraint, which shows that a bank $i$ can acquire money $I_{i, t}$ in exchange for the discounted value of treasury bills carried over from the previous period $B_{i, t-1} / R_{t}^{m}$. For simplicity, we abstract from modeling an interbank market for overnight loans in terms of reserves and the associated (federal funds) rate and assume - consistent with US data - that the treasury repo rate and the federal funds rate coincide, implying that the central bank sets the repo rate $R_{t}^{m}$. Reserves are held by bank $i$ to meet liquidity demands from withdrawals of deposits

$$
\mu D_{i, t-1} \leq I_{i, t}+M_{i, t-1}
$$

Banks supply loans to firms at the price $1 / R_{t}^{L}$ leading to a risk-free payoff $L_{i, t}$ in period $t+1$. They can further invest in short-term government bonds (i.e. treasury bills) that are issued at the price $1 / R_{t}$. Given that the bank $i$ transferred bonds to the central bank under outright sales and that it repurchases treasuries $B_{i, t}^{R}=R_{t}^{m} M_{i, t}^{R}$ from the central bank, its holdings of treasuries before it enters the asset market equals $B_{i, t-1}+B_{i, t}^{R}-\Delta B_{i, t}^{C}$ or $B_{i, t-1}+R_{t}^{m} M_{i, t}^{R}-R_{t}^{m} I_{i, t}$ and its money holdings equals $M_{i, t-1}-R_{t}^{m} M_{i, t}^{R}+I_{i, t}$. Hence, bank

federal funds rate, non-money market rates also tend to differ from the latter.

${ }^{17}$ It should be noted that the introduction of interest on required and excess reserves by the US Federal Reserve during the recent financial crisis has been aimed at enhancing the control over the effective federal funds rate. By setting the interest rate on reserves equal to the target rate (and thereby equal to the repo rate) the central bank eliminates the banks' costs of reserves, as if the price of reserves actually were zero. 
$i$ 's profits $P_{t} \varphi_{i, t}^{B}$ are given by

$$
\begin{aligned}
P_{t} \varphi_{i, t}^{B}= & \left(D_{i, t} / R_{t}^{D}\right)-D_{i, t-1}-M_{i, t}+M_{i, t-1}-I_{i, t}\left(R_{t}^{m}-1\right) \\
& -\left(B_{i, t} / R_{t}\right)+B_{i, t-1}-\left(L_{i, t} / R_{t}^{L}\right)+L_{i, t-1}+A_{i, t} / R_{t}^{A}-A_{i, t-1}
\end{aligned}
$$

where $A_{i, t}$ denotes a risk-free one-period interbank deposit liability issued at the price $1 / R_{t}^{A}$, which cannot be withdrawn before maturity. Thus, $R_{t}^{A}$ is the rate at which banks can freely borrow and lend among each other. Given that a model period is assumed to span three months, $R_{t}^{A}$ corresponds to the 3-month US-LIBOR applied for the empirical analysis (see Section 2). Notably, the aggregate stock of reserves only changes with the central bank money supply, $\int_{0}^{1} M_{i, t} d i=\int_{0}^{1}\left(M_{i, t-1}+I_{i, t}-M_{i, t}^{R}\right) d i$, and is fully backed by treasury bills, whereas demand deposits can be created by the banking sector subject to (9). Banks maximize the sum of discounted profits, $E_{t} \sum_{k=0}^{\infty} p_{t, t+k} \varphi_{i, t+k}^{B}$, where $p_{t, t+k}$ denotes the stochastic discount factor $p_{t, t+k}=\beta^{k} \lambda_{t+k} / \lambda_{t}$, subject to the money supply constraint (8), the liquidity constraint (9), the budget constraint (10), and the borrowing constraints $\lim _{s \rightarrow \infty} E_{t}\left[p_{t, t+k}\left(L_{i, t+s}-D_{i, t+s}-A_{i, t+s}\right) / P_{t+s}\right] \geq 0, B_{i, t} \geq 0$, and $M_{i, t} \geq 0$. The first order conditions with respect to deposits, bonds, loans, money holdings, reserves and one-period deposit liabilities can be written as

$$
\begin{aligned}
\frac{1}{R_{t}^{D}} & =\beta E_{t} \frac{\lambda_{t+1}}{\lambda_{t}} \frac{1+\mu \varkappa_{i, t+1}}{\pi_{t+1}}, \\
\frac{1}{R_{t}} & =\beta E_{t} \frac{\lambda_{t+1}}{\lambda_{t}} \frac{1+\eta_{i, t+1}}{\pi_{t+1}}, \\
\frac{1}{R_{t}^{L}} & =\beta E_{t} \frac{\lambda_{t+1}}{\lambda_{t}} \pi_{t+1}^{-1}, \\
1 & =\beta E_{t} \frac{\lambda_{t+1}}{\lambda_{t}} \frac{1+\varkappa_{i, t+1}}{\pi_{t+1}}, \\
\varkappa_{i, t}+1 & =R_{t}^{m}\left(\eta_{i, t}+1\right), \\
R_{t}^{A} & =R_{t}^{L},
\end{aligned}
$$

where $\varkappa_{i, t}$ and $\eta_{i, t}$ denote the multipliers on the liquidity constraint (9) and the money supply constraint (8), respectively. Further, the following complementary slackness conditions hold in the bank's optimum $i$.) $0 \leq b_{i, t-1} \pi_{t}^{-1}-R_{t}^{m} i_{i, t}, \eta_{i, t} \geq 0, \eta_{i, t}\left(b_{i, t-1} \pi_{t}^{-1}-R_{t}^{m} i_{i, t}\right)=0$, and ii.) $0 \leq i_{i, t}+m_{i, t-1} \pi_{t}^{-1}-\mu d_{i, t-1} \pi_{t}^{-1}, \varkappa_{i, t} \geq 0, \varkappa_{i, t}\left(i_{i, t}+m_{i, t-1} \pi_{t}^{-1}-\mu d_{i, t-1} \pi_{t}^{-1}\right)=0$, where $d_{i, t}=d_{i, t} / P_{t}, m_{i, t}=M_{i, t} / P_{t}, b_{i, t}=B_{i, t} / P_{t}$, and $i_{i, t}=I_{i, t} / P_{t}$, as well as (3) with equality and the associated transversality conditions.

For a preview on equilibrium properties, compare (11) with (7) to get $E_{t}\left[\frac{\lambda_{t+1}+\mu \psi_{t+1}}{\lambda_{t}} \pi_{t+1}^{-1}\right]=E_{t}\left[\frac{\lambda_{t+1}}{\lambda_{t}}\left(1+\varkappa_{i, t+1} \mu\right) \pi_{t+1}^{-1}\right]$. Given that all banks will behave in an identical way (i.e. $\varkappa_{i, t}=\varkappa_{t}$ ), the latter condition is satisfied if $\varkappa_{t}=\psi_{t} / \lambda_{t}$. Hence, the equilibrium versions of the conditions (14) and (15) imply $\left(\psi_{t}+\lambda_{t}\right) / \lambda_{t}=R_{t}^{m}\left(\eta_{t}+1\right)$ 
and $\beta \pi_{t+1}^{-1}\left(\lambda_{t+1}+\psi_{t+1}\right)=\lambda_{t}$, which can - by using the equilibrium version of households' condition (5) - be combined to

$$
\eta_{t}=\left(R_{t}^{I S} / R_{t}^{m}\right)-1
$$

where $R_{t}^{I S}$ denotes the nominal marginal rate of intertemporal substitution of consumption $R_{t}^{I S}=\xi_{t} u_{c, t} / \beta E_{t}\left(\xi_{t+1} u_{c, t+1} / \pi_{t+1}\right)$, which measures the marginal valuation of money by the private sector. ${ }^{18}$ Condition (17) implies that the money supply constraint (8) is binding if the central bank sets the policy rate $R_{t}^{m}$ below $R_{t}^{I S}$. Notably, these two rates are typically assumed to be identical in standard macroeconomic models, including studies on fiscal multipliers at the ZLB (see Christiano et al., 2011 or Eggertsson, 2011). Here, these rates can differ by a liquidity premium, which disappears only if money is supplied in a way that makes eligible assets (like treasury bills) abundant. ${ }^{19}$ Substituting out $\varkappa_{t}$ in the equilibrium version of (14) with $\varkappa_{t}=\psi_{t} / \lambda_{t}$ and combining with the equilibrium version of (5), leads to

$$
\psi_{t}=\xi_{t} u_{c, t}\left(1-1 / R_{t}^{I S}\right)
$$

which implies that the household's liquidity constraint (2) as well as the bank's liquidity constraint (9) are binding if $R_{t}^{I S}$ is strictly larger than one. Hence, liquidity might still be positively valued by households and banks, i.e. $R_{t}^{I S}>1$, even when the policy rate is at the zero lower bound, $R_{t}^{m}=1$. The relation between the equilibrium values of the various interest rates $\left(R_{t}^{m}, R_{t}^{D}, R_{t}^{L}, R_{t}\right.$, and $\left.R_{t}^{I S}\right)$ will be discussed in Section 3.5.

\subsection{Firms}

There are intermediate goods producing firms, which sell their goods to monopolistically competitive retailers. The latter sell a differentiated good to bundlers who assemble final goods using a Dixit-Stiglitz technology. Intermediate goods producing firms are identical, perfectly competitive, owned by households, and produce an intermediate good $y_{t}^{m}$ with labor $n_{t}$ and physical capital $k_{t-1}$. They produce according to the production function

$$
y_{t}^{m}=n_{t}^{\alpha} k_{t-1}^{1-\alpha}, \quad \alpha \in(0,1)
$$

and sells the intermediate good to retailers at the price $P_{t}^{m}$. Physical capital is owned by firms and capital accumulation is associated with adjustment costs: $k_{t}=(1-\delta) k_{t-1}+x_{t} \Lambda_{t}$, where $\delta$ is the rate of depreciation, $x_{t}$ denotes investment expenditures, and investment adjustment costs are $\Lambda\left(x_{t} / x_{t-1}\right)=1-\varsigma \frac{1}{2}\left(x_{t} / x_{t-1}-1\right)^{2}$. To induce a demand for bank loans, we neglect retained earnings and assume that firms rely on bank loans to finance investment expenditures

\footnotetext{
${ }^{18}$ Agents are willing to spend $R_{t}^{I S}-1$ to transform one unit of an illiquid asset, i.e. an asset that is not accepted as a means of payment today and delivers one unit of money tomorrow, into one unit of money today.

${ }^{19}$ For example, the latter might have been the case after the US Federal Reserve increased the supply of reserves via large scale asset purchases and thus after expansionary fiscal policies have been conducted in the US.
} 
that have to be made before goods are sold. Hence, firms' loan demand satisfies:

$$
L_{t} / R_{t}^{L} \geq P_{t} x_{t}
$$

As firms are committed to fully repay their liabilities, bank loans are risk-free. The problem of a representative firm can then be summarized as max $E_{t} \sum_{k=0}^{\infty} p_{t, t+k} \varrho_{t+k}$, where $\varrho_{t}$ denotes real dividends $\varrho_{t}=\left(P_{t}^{m} / P_{t}\right) n_{t}^{\alpha} k_{t-1}^{1-\alpha}-w_{t} n_{t}-x_{t}-l_{t-1} \pi_{t}^{-1}+l_{t} / R_{t}^{L}$, subject to capital accumulation. The first order conditions for working time, loans, investments, and capital can be summarized by $w_{t}=m c_{t} \alpha y_{t}^{m} n_{t}^{-1}$,

$$
\begin{aligned}
1+\gamma_{t} & =q_{t}\left[\Lambda_{t}+\left(x_{t} / x_{t-1}\right) \Lambda_{t}^{\prime}\right]-E_{t}\left[p_{t, t+1} q_{t+1}\left(x_{t+1} / x_{t}\right)^{2} \Lambda_{t+1}^{\prime}\right], \\
q_{t} & =E_{t}\left[p_{t, t+1}\left((1-\alpha) m c_{t+1} y_{t+1}^{m} k_{t}^{-1}+(1-\delta) q_{t+1}\right)\right], \\
1+\gamma_{t} & =R_{t}^{L} E_{t}\left[p_{t, t+1} \pi_{t+1}^{-1}\right],
\end{aligned}
$$

where $m c_{t}=P_{t}^{m} / P_{t}$ denotes real marginal costs, $q_{t}$ the price of physical capital in terms of the final good, and $\gamma_{t}$ the multiplier on the loan demand constraint (20). In absence of financial market frictions, the Modigliani-Miller theorem applies here, such that the multiplier $\gamma_{t}$ equals zero. This can immediately be seen from combining banks' loan supply condition (13) with the firm's loan demand condition (23), implying $\gamma_{t}=0$. Hence, the loan demand constraint (20) is slack, such that the firm's investment decision is undistorted.

Monopolistically competitive retailers buy intermediate goods $y_{t}^{m}$ at the price $P_{t}^{m}$. A retailer $h \in[0,1]$ relabels the intermediate good to $y_{h, t}$ and sells it at price $P_{h, t}$ to perfectly competitive bundlers, who bundle the goods $y_{h, t}$ to the final consumption good $y_{t}$ with the technology $y_{t}^{\frac{\varepsilon-1}{\varepsilon}}=\int_{0}^{1} y_{h, t}^{\frac{\varepsilon-1}{\varepsilon}} d h$, where $\varepsilon>1$. The cost minimizing demand for $y_{h, t}$ is therefore given by $y_{h, t}=\left(P_{h, t} / P_{t}\right)^{-\varepsilon} y_{t}$. Retailers set their prices to maximize profits, where we consider a nominal rigidity in form of staggered price setting. Each period, a measure $1-\phi$ of randomly selected retailers may reset their prices independently of the time elapsed since the last price setting, while a fraction $\phi \in[0,1)$ of retailers do not adjust their prices. The fraction $1-\phi$ of retailers set their prices to maximize the expected sum of discounted future profits, $\max _{\bar{P}_{h, t}} E_{t} \sum_{s=0}^{\infty} \phi^{s} p_{t, t+s}\left(\bar{P}_{h, t} y_{h, t+s}-P_{t+s} m c_{t+s} y_{h, t+s}\right)$, s.t. $y_{h, t+s}=\bar{P} P_{h, t}{ }^{-\epsilon} P_{t+s}^{\epsilon} y_{t+s}$. The first order condition for their price $\bar{P}_{h, t}$ is given by $Z_{t}=\frac{\varepsilon}{\varepsilon-1} Z_{1, t} / Z_{2, t}$, where $Z_{t}=\bar{P}_{h, t} / P_{t}$, $Z_{1, t}=c_{t}^{-\sigma} y_{t} m c_{t}+\phi \beta E_{t} \pi_{t+1}^{\varepsilon} Z_{1, t+1}$ and $Z_{1, t}=c_{t}^{-\sigma} y_{t}+\phi \beta E_{t} \pi_{t+1}^{\varepsilon-1} Z_{2, t+1}$. With perfectly competitive bundlers and the homogeneous bundling technology, the price index $P_{t}$ for the final consumption good satisfies $P_{t}^{1-\varepsilon}=\int_{0}^{1} P_{h, t}^{1-\varepsilon} d h$. Using the demand constraint, we obtain $1=(1-\phi) Z_{t}^{1-\varepsilon}+\phi \pi_{t}^{\varepsilon-1}$.

Aggregate intermediate output is then given by $y_{t}^{m}=n_{t}^{\alpha} k_{t-1}^{1-\alpha}$, while price dispersion across retailers affects aggregate final output. Specifically, the market clearing condition in the intermediate goods market, $y_{t}^{m}=\int_{0}^{1} y_{h, t} d h$, gives $n_{t}^{\alpha} k_{t-1}^{1-\alpha}=\int_{0}^{1}\left(P_{h, t} / P_{t}\right)^{-\varepsilon} y_{t} d h \Leftrightarrow y_{t}=$ 
$n_{t}^{\alpha} k_{t-1}^{1-\alpha} / s_{t}$, where $s_{t} \equiv \int_{0}^{1}\left(P_{h, t} / P_{t}\right)^{-\varepsilon} d h$ and $s_{t}=(1-\phi) Z_{t}^{-\varepsilon}+\phi s_{t-1} \pi_{t}^{\varepsilon}$ given $s_{-1}$.

\subsection{Public sector}

The public sector consists of a government and a central bank. The government purchases goods, raises taxes, pays and receives transfers, and issues short-term debt $B_{t}^{T}$ which is held by banks, $B_{t}$, and by the central bank, $B_{t}^{C}$, i.e. $B_{t}^{T}=B_{t}+B_{t}^{C}$. These securities are modelled as one-period risk-free bonds and correspond to treasury bills, given that a period lasts three months. Following Schabert (2015), we assume that the supply of treasury bills is exogenously determined and that they are issued at a constant growth rate $\Gamma$ satisfying

$$
B_{t}^{T}=\Gamma B_{t-1}^{T},
$$

where $\Gamma>\beta$. By (24), we do not aim at modelling the evolution of total public debt that also consists of government bonds with longer maturity. The latter might grow with a rate different from $\Gamma$, which will not be modelled here to keep the exposition simple. Hence, (24) rather describes the supply of money market instruments that the central bank declares eligible. For the analysis of fiscal policy shocks, we assume that a flat-rate income $\operatorname{tax} \tau_{t}^{n}$ and government expenditures $g_{t}$ are generated by stochastic processes:

$$
\begin{gathered}
g_{t}=\rho_{g} g_{t-1}+\left(1-\rho_{g}\right) g+\varepsilon_{g, t}, \\
\tau_{t}^{n}=\rho_{\tau} \tau_{t-1}^{n}+\left(1-\rho_{\tau}\right) \tau^{n}+\varepsilon_{\tau, t},
\end{gathered}
$$

where $\rho_{g, \tau} \in(0,1), g>0, \tau^{n} \in(0,1)$ and the innovations $\varepsilon_{g, t}$ and $\varepsilon_{\tau, t}$ have zero mean and are i.i.d.. ${ }^{20}$ To isolate effects of these fiscal policy shocks, we assume that the government can raise or transfer revenues in a non-distortionary way, $P_{t} \tau_{t}$. Further accounting for the transfers $P_{t} \tau_{t}^{m}$ from the central bank, the government budget constraint is given by

$$
\left(B_{t}^{T} / R_{t}\right)+\tau_{t}^{n} P_{t} w_{t} n_{i, t}+P_{t} \tau_{t}^{m}=P_{t} g_{t}+B_{t-1}^{T}+P_{t} \tau_{t}
$$

The central bank supplies money in exchange for treasury bills either outright, $M_{t}$, or under repos $M_{t}^{R}$. At the beginning of each period, the central bank's stock of treasuries equals $B_{t-1}^{C}$ and the stock of outstanding money equals $M_{t-1}$. It then receives an amount $\Delta B_{t}^{C}$ of treasuries in exchange for newly supplied money $I_{t}=M_{t}-M_{t-1}+M_{t}^{R}$, and, after repurchase agreements are settled, its holdings of treasuries and the amount of outstanding money reduce by $B_{t}^{R}$ and by $M_{t}^{R}$, respectively. Before the asset market opens, where the central bank can reinvest its payoffs from maturing securities in T-bills $B_{t}^{C}$, it holds an amount equal to $\Delta B_{t}^{C}+B_{t-1}^{C}-B_{t}^{R}$. Its budget constraint is thus given by $\left(B_{t}^{C} / R_{t}\right)+P_{t} \tau_{t}^{m}=\Delta B_{t}^{C}+$

\footnotetext{
${ }^{20}$ We abstract from explicitly accounting for the bounds $g_{t} \geq 0$ and $\tau_{t}^{n}<1$ and, in the analytical evaluation, assume that they are satifsfied. In the numerical analysis, we choose the variances of $\varepsilon_{\tau, t}$ and $\varepsilon_{g, t}$ such that $g_{t}<0$ and $\tau_{t}^{n}>1$ are extremely unlikely.
} 
$B_{t-1}^{C}-B_{t}^{R}+M_{t}-M_{t-1}-\left(I_{t}-M_{t}^{R}\right)$, which after substituting out $I_{t}, B_{t}^{R}$, and $\Delta B_{t}^{C}$ using $\Delta B_{t}^{C}=R_{t}^{m} I_{t}$, can be simplified to $\left(B_{t}^{C} / R_{t}\right)-B_{t-1}^{C}=R_{t}^{m}\left(M_{t}-M_{t-1}\right)+\left(R_{t}^{m}-1\right) M_{t}^{R}-P_{t} \tau_{t}^{m}$. Following central bank practice, we assume that interest earnings are transferred to the government, $P_{t} \tau_{t}^{m}=B_{t}^{C}\left(1-1 / R_{t}\right)+\left(R_{t}^{m}-1\right)\left(M_{t}-M_{t-1}+M_{t}^{R}\right)$, and that maturing assets are rolled over, such that holdings of treasuries evolve according to $B_{t}^{C}-B_{t-1}^{C}=M_{t}-M_{t-1}$. Further restricting initial values to $B_{-1}^{C}=M_{-1}$ leads to the central bank balance sheet

$$
B_{t}^{C}=M_{t}
$$

Regarding the implementation of monetary policy, we assume that the central bank sets the policy rate according to a Taylor-type feedback rule, while respecting the ZLB:

$$
R_{t}^{m}=\max \left\{1,\left(R_{t-1}^{m}\right)^{\rho_{R}}\left(R^{m}\right)^{1-\rho_{R}}\left(\pi_{t} / \pi\right)^{\rho_{\pi}\left(1-\rho_{R}\right)}\left(y_{t} / \widetilde{y}_{t}\right)^{\rho_{y}\left(1-\rho_{R}\right)}\right\},
$$

where $\widetilde{y}_{t}$ is the efficient level of output and $\rho_{\pi} \geq 0, \rho_{y} \geq 0, \rho_{R} \geq 0$ and $R^{m} \geq 1$. The target inflation rate $\pi$ is controlled by the central bank and is assumed to equal the growth rate of treasuries $\Gamma$, for simplicity. In Schabert (2015), it is shown how the central bank can implement its inflation target even if $\pi \neq \Gamma$. Finally, the central bank fixes the fraction of money supplied under repurchase agreements relative to money supplied outright at $\Omega \geq 0$ : $M_{t}^{R}=\Omega M_{t}$. For the quantitative analysis, $\Omega$ will be set at a sufficiently large value to ensure that central bank money injections $I_{t}$ are non-negative.

\subsection{Equilibrium properties}

Given that all firms, retailers, and banks behave in an identical way, we can omit the indices $h$ and $i$. A definition of the rational expectations equilibrium can be found in Appendix B. It should be noted that banks are irrelevant for the equilibrium allocation as financial markets are frictionless, such that the Modigliani-Miller theorem applies here. The main difference to a conventional New Keynesian model is thus the existence of the money supply constraint (8), which ensures that reserves are fully backed by treasuries. Notably, interest rates on non-eligible assets exceed the policy rate and the treasury rate by a liquidity premium if (8) is binding. This is the case when the central bank supplies money at a lower price than households would be willing to pay, $R_{t}^{m}<R_{t}^{I S}$, such that households earn a positive rent and are willing to increase their money holdings. Given that access to money is restricted by holdings of treasury bills, the money supply constraint (8) will be binding, indicating a positive liquidity value of treasuries, $\eta_{t}>0$ (see 17). ${ }^{21}$ The treasury rate $R_{t}$, which satisfies (12), can, by applying the equilibrium versions of (5), (14), (15), and $\varkappa_{t}=\psi_{t} / \lambda_{t}$, be written

\footnotetext{
${ }^{21}$ Notably, a binding money supply constraint (8), which relies on a positive valuation of liquidity, implies that the cash constraint (2) is binding as well, $\psi_{t}>0$.
} 
as

$$
R_{t}=E_{t} R_{t+1}^{m}+\Theta_{t}
$$

where $\Theta_{t}$ collects terms that are higher than first order, implying that the treasury bill rate equals the expected policy rate up to first order. The bank's first order conditions (11), (13), (14), and (16) further imply that the deposit rate $R_{t}^{D}$ exceeds one and is smaller than the interest rates on loans to firms $R_{t}^{L}$ and on one-period interbank loans $R_{t}^{A}$ when liquidity is positively valued, i.e. if $\psi_{t}>0$. Given that both types of loans are assumed to be riskfree, their nominal interest rates are identical (see 16) and in the long-run given by $\pi / \beta$. Combining (13), with $\beta \pi_{t+1}^{-1}\left(\lambda_{t+1}+\psi_{t+1}\right)=\lambda_{t}$ (see 14) and (5) shows that the loan rate $R_{t}^{L}$ and therefore the interbank rate $R_{t}^{A}=R_{t}^{L}$ are identical to the expected marginal rate of intertemporal substitution up to first order:

$$
1 / R_{t}^{A}=E_{t}\left[1 / R_{t+1}^{I S}\right]
$$

According to (28), the money market spread $R_{t}^{A}-R_{t}^{m}$ will be closely related to the spread between the marginal rate of intertemporal substitution and the monetary policy rate $R_{t}^{I S}$ $R_{t}^{m}$, which precisely captures how the model deviates from a standard model. When we derive analytical results in the subsequent section, we focus on the latter to unveil the main mechanism at work, while we present impulse responses of the former to fiscal shocks (that correspond to our empirical results) in the quantitative part of the analysis.

It should be noted that the model reduces to a conventional model if the money supply constraint (8) is slack, i.e. if the multiplier $\eta_{t}$ equals zero, which requires the policy rate to be equal to the nominal marginal rate of intertemporal substitution $R_{t}^{I S}$ (see 17). In this case, the interbank rate $R_{t}^{A}$ is identical to the policy rate at the zero lower bound (see 28). This version of the model is summarized in Definition 2 in Appendix B. Throughout the remaining analysis, we are, however, particularly interested in the case where the policy rate $R_{t}^{m}$ is strictly below the nominal marginal rate of intertemporal substitution $R_{t}^{I S}$, such that the money supply constraint (8) is binding. This can be ensured in a long-run equilibrium (where steady state values are not indexed with $t$ ) if the central bank sets the real policy rate $R^{m} / \pi$ below the long-run real interest rate $1 / \beta$ on non-eligible assets. According to (27), the real treasury rate is then also lower than the real rates on non-eligible assets. In the short-run, $R_{t}^{m}<R_{t}^{I S}$ requires that the central bank is not supplying money in a way that induces liquid assets (i.e. reserves and treasury bills) to be abundant. ${ }^{22}$ Such a policy can be motivated by the fact that a central bank can actually enhance welfare by supplying money

\footnotetext{
${ }^{22} \mathrm{Put}$ differently, $R_{t}^{I S}$ should not endogenously fall to the level of the policy rate. If, for example, the central bank strongly increases the supply of money, the associated upward shift in consumption would increase the growth rate of the marginal utility of consumption and thereby drive down $R_{t}^{I S}$, until it reaches the policy rate.
} 
against scarce collateral, as shown by Schabert (2015) in a related model. Further, note that as long as $R_{t}^{I S}$ does not hit the zero lower bound, i.e. $R_{t}^{I S}>1$, the demand for money is well defined, as the liquidity constraints of households (2) and banks (9) are binding (see 18).

\section{$4 \quad$ Fiscal policy effects}

In this Section, we examine the effects of shocks to the fiscal policy instruments, $g_{t}$ and $\tau_{t}$, for the case where the money supply constraint (8) is binding, i.e. where $\eta_{t}>0$ (see 17), which allows reproducing the observations regarding the interest rate spread as documented in Section 2. When the money supply constraint is not binding (see Definition 2 in Appendix B), the model is actually identical to the model examined by Linnemann and Schabert (2003), where it is shown that fiscal policy shocks have conventional neoclassical effects when the ZLB is slack (see also Woodford, 2011), i.e. the fiscal multiplier is smaller than one as government spending crowds out private absorption. ${ }^{23}$ In the first part of this Section, we examine fiscal policy shocks in a simplified version of the model, which can be solved analytically. In the second part, we apply a calibrated version of the model and present impulse response functions. Specifically, we examine fiscal policy effects on interest rates and real activity for the case where the policy rate is temporarily at the zero lower bound.

\subsection{Analytical results}

To facilitate the derivation of analytical results, we simplify the model by applying the parameter values $\alpha=1, h=0, \rho_{g, \tau}=0, \pi=\Gamma=1$, and $\Omega \rightarrow \infty$, which imply that there is no capital accumulation, no habit formation, no autocorrelation of fiscal shocks, long-run price stability, and that money is exclusively supplied under repos. We further simplify monetary policy by restricting the policy rate to be set according to (26) with $\rho_{R, y}=0$. For these simplifying parameter values, we log-linearize the model at a steady state with a binding money supply constraint (8), i.e. with $R^{m} / \pi<1 / \beta$ (see 17). We further assume for this subsection that shocks are sufficiently small such that the ZLB is never binding. A definition of the rational expectations equilibrium of this model version can be found in Appendix C. Before we analyze the effects of fiscal policy shocks, we examine conditions for equilibrium determinacy, i.e. for the existence and the uniqueness of locally convergent equilibrium sequences, which are summarized in the following proposition.

Proposition 1 For $h=\rho_{R, y, g, \tau}=0, \alpha=\pi=\Gamma=1, R^{m} / \pi<1 / \beta$, and $\Omega \rightarrow \infty$, the equilibrium under a slack $Z L B$ is locally determined if but not only if

$$
\rho_{\pi}<\left[(1+\beta) \chi^{-1}+1-\sigma\right] / \sigma,
$$

where $\chi=(1-\phi)(1-\beta \phi) / \phi$.

\footnotetext{
${ }^{23}$ Effects of fiscal policy shocks for this version are included in Figures 4 and 5, below.
} 
Proof. See Appendix C.

Condition (29) in Proposition 1 implies that, under a binding money supply constraint (8), an active monetary policy $\left(\rho_{\pi}>1\right)$ is neither necessary nor relevant for equilibrium determinacy in this model and that the central bank can peg the policy rate $\left(\rho_{\pi}=0\right)$ at any non-negative rate without inducing indeterminacy. This property is mainly due to a non-explosive supply of eligible assets, i.e. treasuries, by which reserves are backed and which provide a nominal anchor for monetary policy (similar to a constant growth rate of money). ${ }^{24}$ Multiple equilibria do therefore not occur even if the central bank applies a passive $\left(\rho_{\pi}<1\right)$ interest rate policy. Notably, the well-known Taylor principle does not apply here, given that the central bank does not control the marginal rate of intertemporal substitution. It should further be noted that the sufficient condition (29) is far from being restrictive for a broad set of reasonable parameter values. Consider, for example, the parameter values $\beta=0.9948, \sigma=2$ and $\phi=0.8$ (see Section 4.2). Then, $\chi=0.051$ and the upper bound equals 19.04, which is much larger than values typically estimated for the inflation feedback $\rho_{\pi}$.

We now turn to the analysis of fiscal policy effects. We show that fiscal policy shocks, i.e. an increase in government spending and an increase in the tax rate, lead to a decline in private consumption and to an increase in inflation regardless of the level of the mean policy rate and of the inflation feedback parameter $\rho_{\pi}$. We further show that the nominal marginal rate of intertemporal substitution rises in response to an increase in government spending. These results are summarized in the following proposition.

Proposition 2 For $h=\rho_{R, y, g, \tau}=0, \alpha=\pi=\Gamma=1, R^{m} / \pi<1 / \beta, \Omega \rightarrow \infty$, (29), and a slack $Z L B$, an unexpected increase in government spending as well as an unexpected rise in the income tax rate lead, on impact, to a fall in private consumption $c_{t}$ and to an increase in inflation $\pi_{t}$, in the nominal marginal rate of intertemporal substitution $R_{t}^{I S}$, and in the spread $R_{t}^{I S}-R_{t}^{m}$.

\section{Proof. See Appendix C.}

As summarized in Proposition 2, the model predicts that fiscal policy shocks lead to effects that accord to the neoclassical view on fiscal policy (see Baxter and King, 1993, Linnemann and Schabert, 2003, or Woodford, 2011). Notably, these results hold regardless of whether the policy rate is fixed at some non-negative value, $R^{m} \geq 1$, or increased with inflation, given that (29) is satisfied. ${ }^{25}$ An increase in government spending then crowds-out private consumption such that the fiscal multiplier is necessarily smaller than one. ${ }^{26}$ Both types of

\footnotetext{
${ }^{24}$ This result also holds when treasuries grow with a positive rate $\Gamma>1$ (see Schabert, 2015, for details on how the central bank controls long-run inflation in this case).

${ }^{25}$ Even under a peg, there is no equilibrium multiplicity, which has been explored by Mertens and Ravn (2014) to revisit fiscal policy effects at the ZLB.

${ }^{26}$ Likewise, an increase in the labor income tax rate increases inflation and reduces private consumption regardless of the policy rule feedback parameter $\rho_{\pi} \geq 0$.
} 
shocks further tend to increase the nominal marginal rate of intertemporal substitution and its spread to the monetary policy rate. The reason is that the immediate crowding out of private consumption, which is associated with an increase in the consumption growth rate, implies an increase in the real marginal rate of intertemporal substitution, while the increase in inflation also raises the marginal rate of intertemporal substitution in nominal terms. Both effects are even more pronounced when the policy rate is increased with inflation, such that the spread $R_{t}^{I S}-R_{t}^{m}$ increases as well. A rise in the spread would obviously be impossible in a single interest rate framework. Here, the nominal marginal rate of intertemporal substitution endogenously adjusts to the fiscal shocks even when the policy rate is pegged, such that the spread between the monetary policy rate $R_{t}^{m}$ and $R_{t}^{I S}$ increases. The effects on the spread between the interbank rate $R_{t}^{A}$, which follows expectations on $R_{t+1}^{I S}$ (see 28), and the policy rate will be shown below for the calibrated version of the model.

In this model, macroeconomic effects of fiscal policy shocks for a zero policy rate closely relate to the case where the central bank controls the money growth rate and the marginal rate of intertemporal substitution adjusts endogenously. As shown by Linnemann and Schabert (2003) for the case of constant money growth, government expenditure shocks then exert conventional effects, i.e. they lead to a crowding out of private consumption and to a fiscal multiplier smaller than one. These results differ from the results derived in Christiano et al. (2011) and Eggertsson (2011), where not only the monetary policy rate is fixed at zero, but also the nominal marginal rate of intertemporal substitution $R_{t}^{I S}$. To demonstrate that these results also hold for more realistic parameter values, we assess the responses to fiscal shocks for a calibrated version of the model in the subsequent Section.

\subsection{A calibrated version}

We apply standard parameter values (which accord to an interpretation of a period as a quarter) as far as possible. We set the inverses of the elasticities of intertemporal substitution to $\sigma=2$ and $\sigma_{n}=2$, the labor income share to $\alpha=2 / 3$, the habit formation parameter to $h=0.7$, and the depreciation rate to $\delta=0.025$. The elasticity of substitution $\epsilon$ is set to $\epsilon=6$, and the utility parameter $\theta$ is chosen to lead to a steady state working time of $n=1 / 3$. For the benchmark case, we apply for the fraction of non-optimally price adjusting firms $\phi$ and for the investment adjustment cost parameter $\varsigma$, the standard value $\phi=0.8$ and the value $\varsigma=0.065$, which accords to estimates based on disaggregate data (see Groth and Khan, 2010). For the policy rate and the inflation rate, we set the average value equal to the sample mean of the federal funds rate and the CPI inflation rate for the sample 1964.II-2008.II, $R^{m}=1.0635^{1 / 4}$. and $\pi=1.045^{1 / 4}$ (data are from the FRED database). The discount factor $\beta$ is set to $\beta=0.9948$, which implies that the steady state spread between the nominal marginal rate of intertemporal substitution $R^{I S}$ and the monetary policy rate $R^{m}$ equals 0.0028 for annualized 

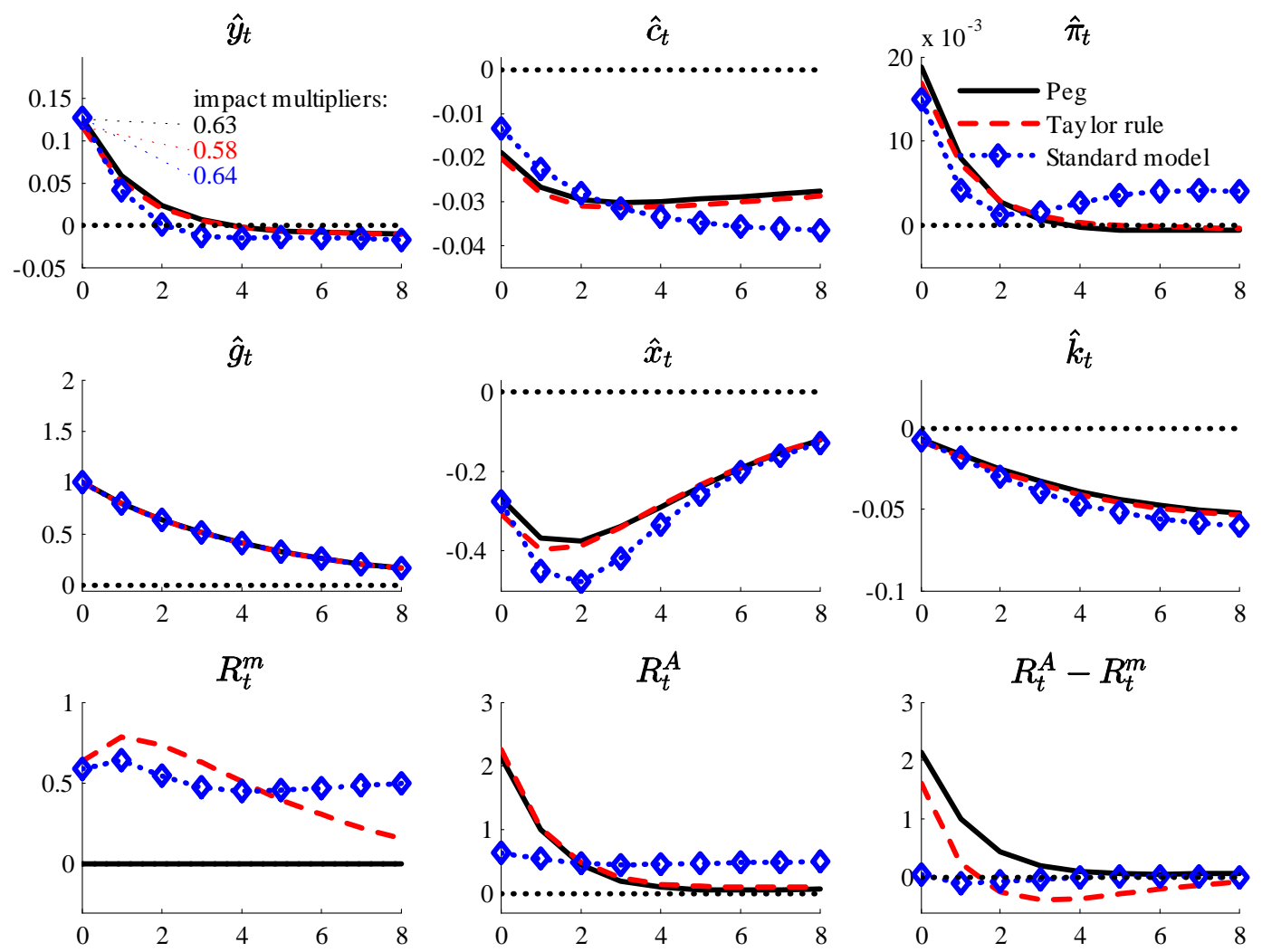

Figure 4: Responses to a government spending shock under a slack ZLB [Notes: Panels 1-6 show relative deviations (in \%) from steady state, absolute reaction (in b.p.) shown in panels 7-9.]

rates, in accordance with the mean spread between the 3-month US-LIBOR and the federal funds rate for the period 1986.I-2013.II (see Figure 10 in Appendix D). The growth rate $\Gamma$ of T-bills (see 24) is set equal to the inflation target, which roughly accords to the growth rate of the stock of T-bills for 1986-2008 (data are from the U.S. Treasury). The model does not account for real growth and thus there is no trend in real money demand, which would have to be accommodated by the central bank by an increasing outright money supply. We thus set the fraction of money supplied under repos, $\Omega$, equal to 1 , for simplicity, which is however not relevant for the results. The policy rate is set according to the interest rate rule (26) with coefficients of the Taylor rule that are set to standard values $\rho_{\pi}=1.5, \rho_{y}=0.05$, and $\rho_{R}=0.8$. Finally, the mean tax rate $\tau^{n}$ and the mean government share $g / y$ are set to 0.2 (see Christiano et al., 2011). Under these parameter values, the equilibrium is locally determinate (which accords to the result summarized in Proposition 1) for all versions of the model considered below. 

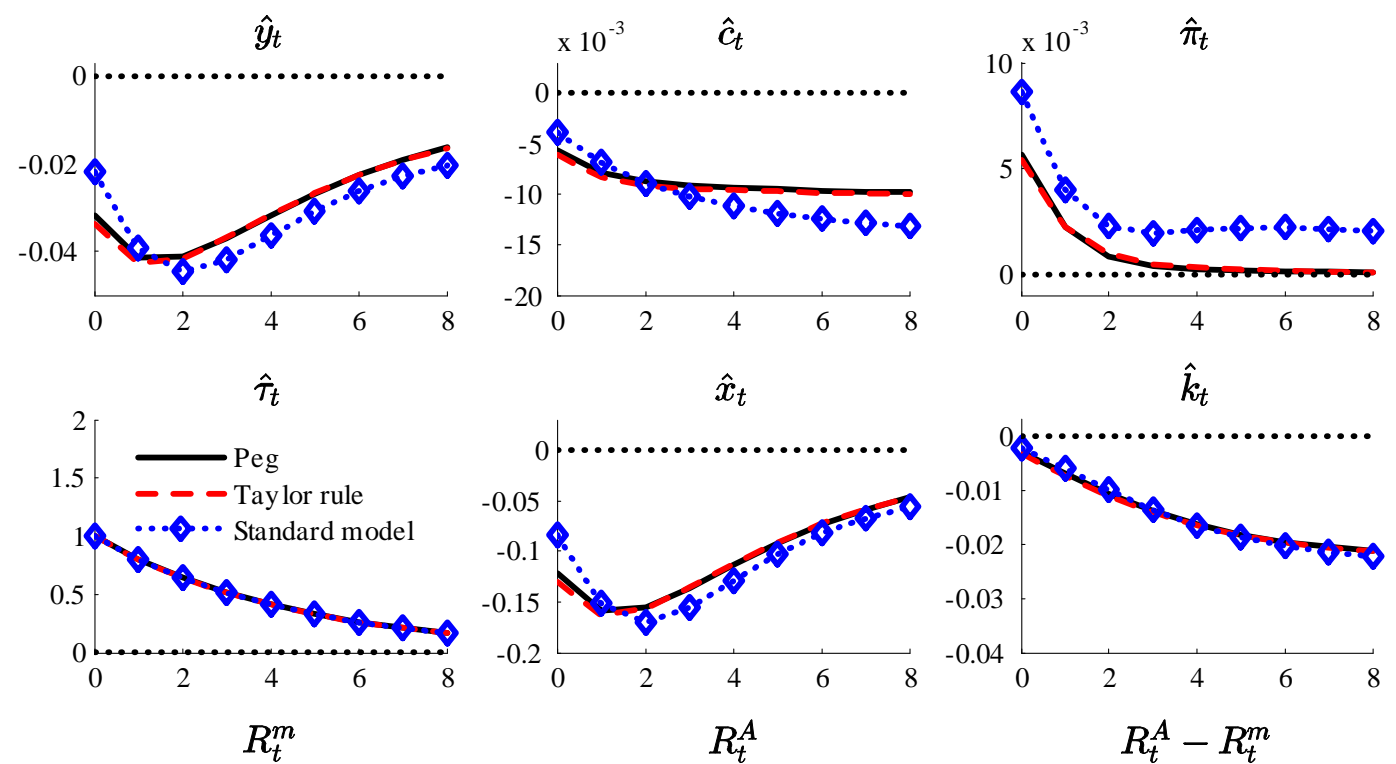

$\hat{x}_{t}$
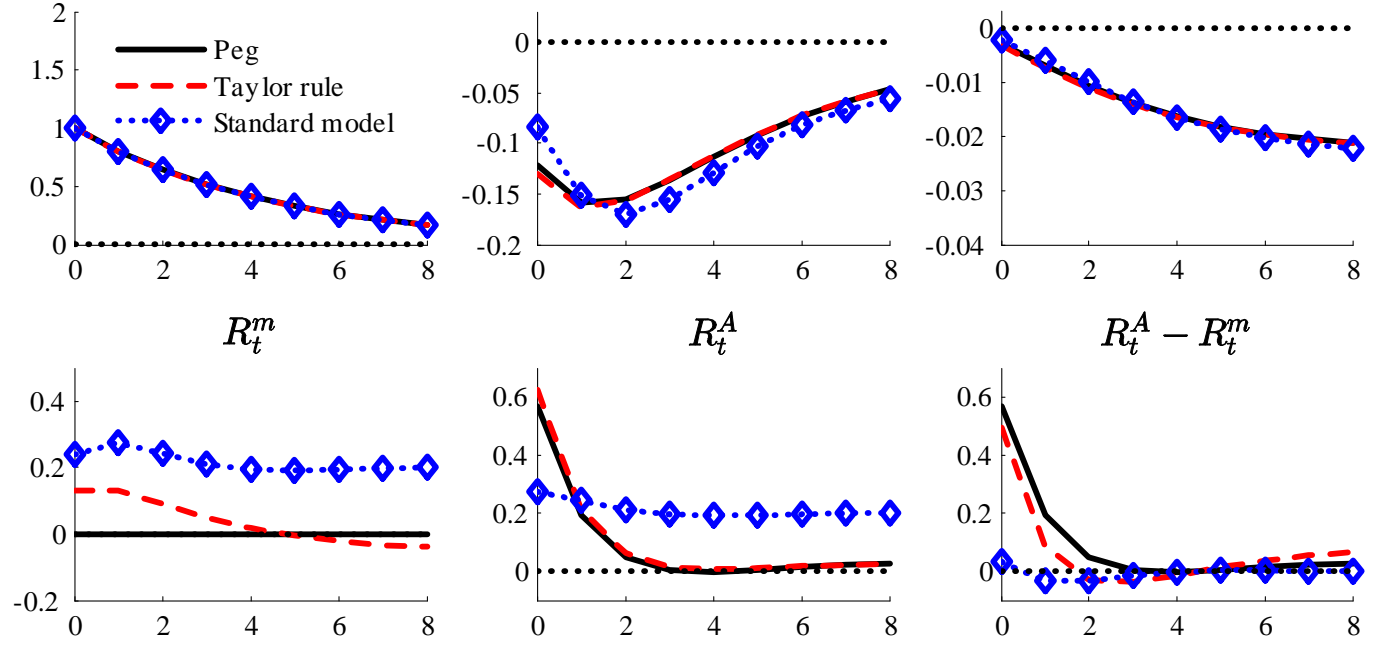

Figure 5: Responses to an income tax rate shock under a slack ZLB [Notes: Panels 1-6 show relative deviations (in \%) from steady state, absolute reaction (in b.p.) shown in panels 7-9]

Impulse responses to fiscal policy shocks Before we look at a ZLB scenario, we examine responses to government spending shocks for the case where the ZLB is slack to demonstrate that the model leads to conventional fiscal policy effects regardless of the reaction of monetary policy as measured by the inflation feedback $\rho_{\pi}$. In contrast to standard New Keynesian models, our model allows to compute fiscal policy effects for a fixed policy rate while ensuring a uniquely determined equilibrium (see Proposition 1). This case will be associated with a maximum multiplier (as monetary policy does not stem against the inflationary effect of fiscal shocks), and is particularly interesting as it should relate to the fiscal multiplier for temporary ZLB episodes.

Figure 4 shows impulse responses to an autocorrelated $\left(\rho_{g}=0.8\right)$ government spending shock amounting to one percent of steady state spending for three model versions. The black solid line refers to an interest rate peg $\left(\rho_{\pi}=\rho_{y}=0\right)$, the red dashed line refers to a policy rate set according to a Taylor rule, and the blue dotted line with diamonds refers to a (standard) version of the model with a Taylor rule and where the policy rate equals the marginal rate of 

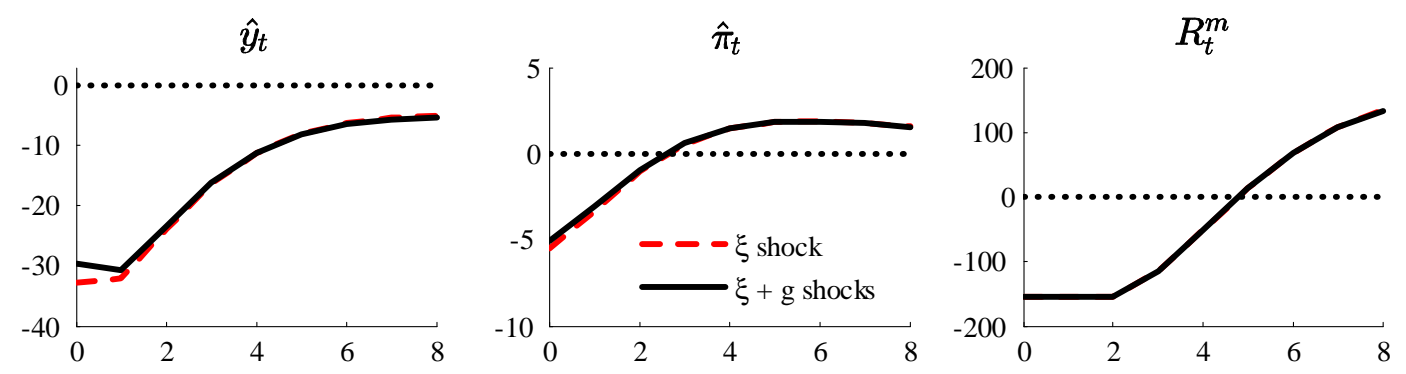

Figure 6: Responses to a preference shock and responses to the same preference shock and a government spending shock in the same period [Notes: Panels 1-2 show relative deviations (in \%) from steady state, absolute reaction (in b.p.) shown in panel 3]

substitution, $R_{t}^{m}=R_{t}^{I S}{ }^{27}$ In all three versions, government spending exerts the well-known wealth effect: higher public consumption crowds out private consumption while it leads to an increase in labor supply such that the fiscal multiplier is positive. Investment falls, while real marginal costs and therefore inflation increase. Even when the policy rate is pegged, consumption is not crowded-in, which differs from the prediction of standard New Keynesian models at the ZLB (see Eggertsson, 2011, or Christiano et al., 2011). Notably, the nominal marginal rate of intertemporal substitution increases in all cases, i.e. regardless of whether the policy rate is pegged or follows a Taylor rule. ${ }^{28}$ In both scenarios where the money supply constraint is binding (see black solid line and red dashed line) the spread between the interbank rate $R_{t}^{A}$ and the policy rate $R_{t}^{m}$ increases, consistent with the empirical evidence provided in Section $2 .{ }^{29}$ Overall, the responses to higher government spending under a binding money supply constraint are not hugely affected by monetary policy pegging the policy rate or adjusting it endogenously according to a Taylor rule. Quantitatively, we find that an increase in government spending tends to be slightly more expansionary under a peg, which is due to the inflation driven increase in the policy rate under a Taylor rule that counteracts the expansionary shock. On impact, the fiscal multiplier equals 0.58 under a Taylor rule and 0.63 when the policy rate is pegged, respectively.

Figure 5 further shows the corresponding responses to an autocorrelated $\left(\rho_{\tau}=0.8\right)$ increase in the labor income tax rate. In accordance with conventional wisdom, both, working time and consumption decline. As wages and real marginal costs increase, inflation rises,

\footnotetext{
${ }^{27}$ In this case, the money supply constraint (8) is slack and the model reduces to a standard New Keynesian model (see Definition 2 in Appendix B).

${ }^{28}$ Notice that the mean policy rate is positive under a Taylor rule such that negative deviations from steady state do not imply negative policy rates. For the standard model, the mean policy rate equals $\pi / \beta$ as usual.

${ }^{29}$ Quantitatively, the maximum response of the spread (1.6 b.p. and 2.1 b.p. for the Taylor rule and the peg, respectively) lies within the confidence interval for the peak response of the spread in our benchmark VAR.
} 

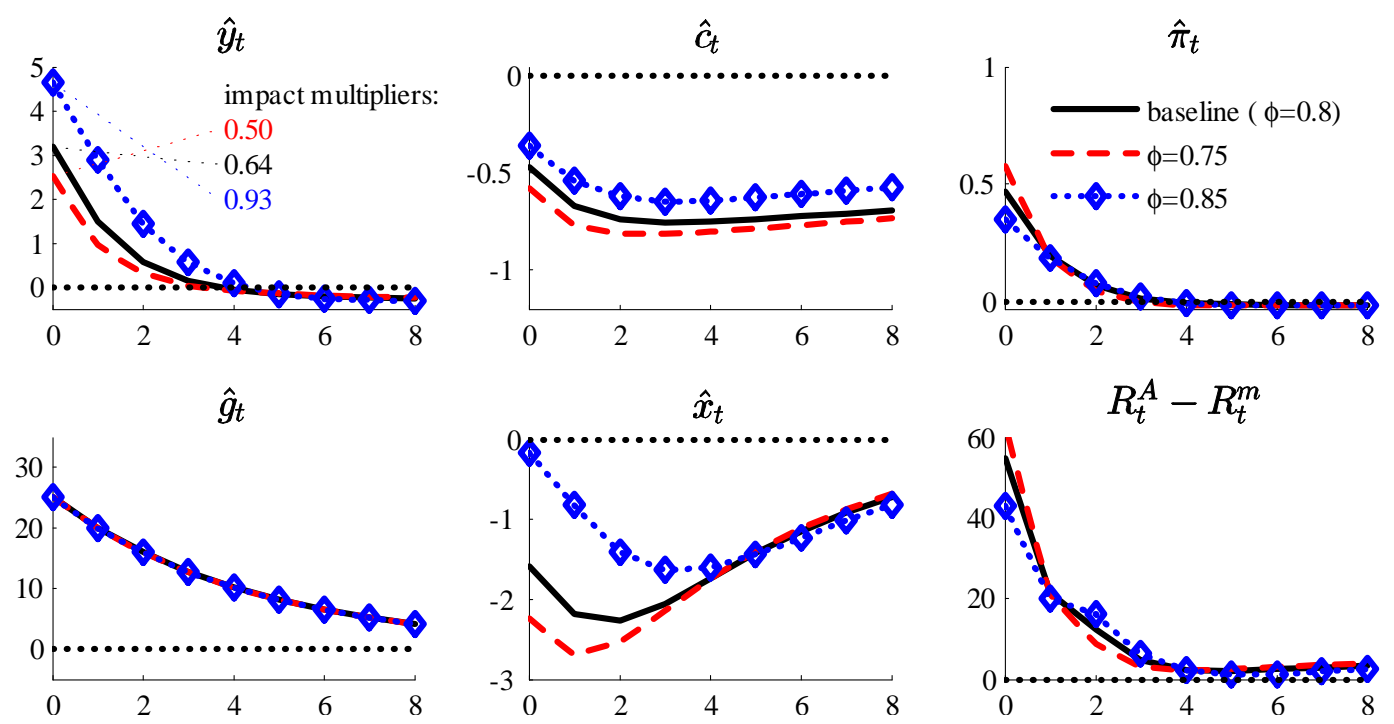

Figure 7: Net effect of government spending shock for different degrees of price rigidity [Notes: Panels 1-5 show relative deviations (in \%) from steady state, absolute reaction (in b.p.) shown in panel 6.$]$

which causes the central bank to increase the policy rate when it applies a Taylor rule. Both versions of the model with the binding money supply constraint unambiguously show that output declines and the money market spread increases regardless of monetary policy, consistent with the results summarized in Proposition 2. Specifically, the fact that the policy rate is pegged does not affect the sign of the responses to higher tax rates.

Fiscal policy shocks at the ZLB We now analyze the model's properties at a temporarily binding zero lower bound. For this, we use the dynare supplement "occbin" developed by Guerrieri and Iacoviello (2014). ${ }^{30}$ We consider the smallest shock to the preference parameter $\xi$ that causes the economy to reach the zero lower bound in the impact period and to remain there for three periods, which suffices for the purpose of this analysis. The red dashed lines in Figure 6 show responses to this shock. The preference shock causes output and inflation to fall such that the central bank lowers the policy rate until the zero lower bound is reached. In order to evaluate the effects of fiscal policy at the zero lower bound, we examine the responses to a government spending shock amounting to $5 \%$ of steady state output that hits the economy in the same period as the preference shock that brings it to the ZLB. In Figure 6 , the black solid lines give the responses when the economy is hit by both shocks. The

\footnotetext{
${ }^{30}$ "Occbin" solves dynamic models with occasionally binding constraints using a first-order perturbation approach. It handles occasionally binding constraints as different regimes of the same model to obtain a piecewise linear solution. While non-linear techniques have been applied to study fiscal policy effects at the ZLB (e.g., Fernández-Villaverde et al., 2012), this approximation suffices for our purposes.
} 

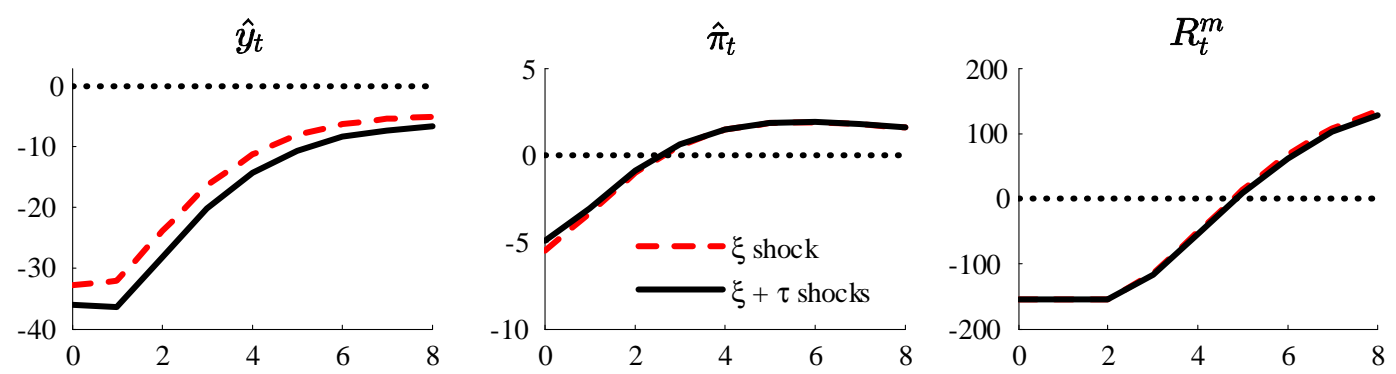

Figure 8: Responses to a preference shock and responses to the same preference shock and an income tax rate shock in the same period [Notes: Panels 1-2 show relative deviations (in \%) from steady state, absolute reaction (in b.p.) shown in panel 3]

results show that the expansionary fiscal policy in fact mitigates the reduction in output and inflation, though to a comparably small extent, while the sequences of the policy rate are virtually identical.

To take a closer look at the effects of expansionary fiscal policy, Figure 7 presents the net effects of the government spending shock, i.e. the responses to both shocks net of the responses to the preference shock alone. Here, we show results for different degrees of price rigidity $\phi$, i.e. for the benchmark value 0.8 (black solid line), for 0.75 (red dashed line), and for 0.85. (blue dotted line with circles). Overall, Figure 7 shows that the fiscal impulse has conventional effects as it crowds-out private absorption and increases output as well as inflation, even though the policy rate is temporarily at the ZLB. As before, the government spending shock leads to a rise in the marginal rate of intertemporal substitution and with the policy rate being fixed at the ZLB for the first periods the spread between the interbank rate and the monetary policy rate $R_{t}^{A}-R_{t}^{m}$ rises as well. Overall, the impulse responses from the calibrated version accord to the results derived for the simplified version in Proposition 2. On impact, fiscal spending is increased by $5 \%$ of steady state GDP which, for the baseline value of $\phi=0.8$, induces a rise in GDP by $3.18 \%$ of its steady state value. Hence, the fiscal multiplier on impact equals 0.64 and is thus well below the numbers suggested by e.g. Christiano et al. (2011), even though the economy is at the ZLB. A comparison of the different lines in Figure 7 further shows a fairly intuitive result, namely, that the fiscal multiplier is larger the more prices are sticky. This result is particularly remarkable, as the opposite has typically been found in related studies on the ZLB, as stressed by Cochrane (2015). ${ }^{31}$

Finally, we conduct the corresponding experiment for an increase in the labor income tax rate when the economy is hit by an adverse preference shock, such that the policy rate is again lowered until it reaches the ZLB. Consistent with the results from the previous analysis, the

\footnotetext{
${ }^{31}$ The fiscal multiplier further increases with the autocorrelation of the fiscal shocks and the investment adjustment costs, though it does not exceed one (see Figures in Appendix D).
} 

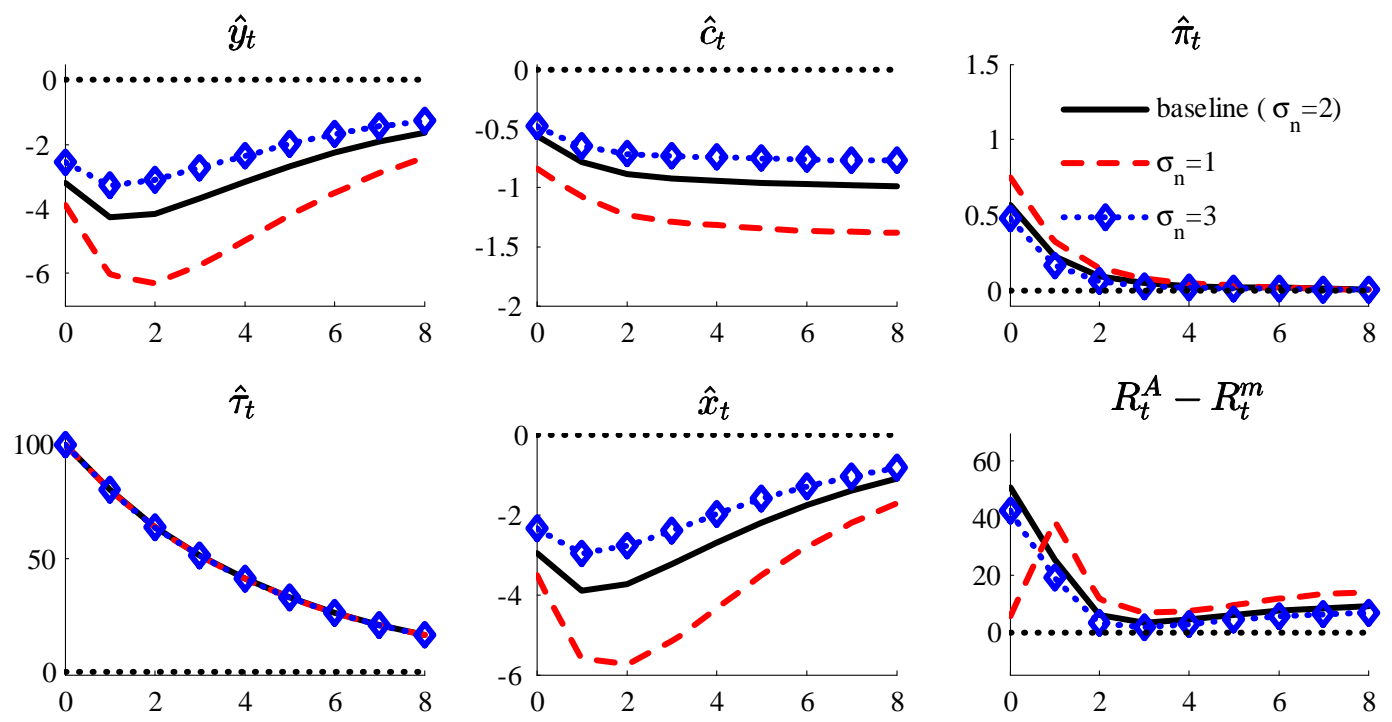

Figure 9: Net effect of an income tax rate shock for different labor supply elasticities [Notes: Panels 1-5 show relative deviations (in \%) from steady state, absolute reaction (in b.p.) shown in panel 6]

adverse effect on real activity is more pronounced when the labor income tax rate is increased (see black solid line in Figure 8). The net effects of the tax rate increase are shown in more detail in Figure 9. It confirms that the tax increase leads to conventional effects, which are - intuitively - more pronounced when labor supply is more elastic $\left(1 / \sigma_{n}\right.$ takes higher values). The adverse effect of a tax rate increase is intuitive and remarkably different from the paradoxic results stemming from standard New Keynesian models at the ZLB, where tax shocks can exert expansionary effects (see Eggertsson, 2011).

\section{Conclusion}

In this paper, we reconsider fiscal policy effects when the monetary policy rate is at the zero lower bound. We provide evidence for US data showing that a short-term interest rate that is more relevant for private borrowing (i.e. the US-LIBOR) tends to exceed the monetary policy rate and that the spread tends to increase with government expenditures. We augment a standard New Keynesian model to replicate this finding by introducing a liquidity premium between the marginal rate of intertemporal substitution and the monetary policy rate. Applying this model, we show that fiscal policy shocks exert conventional effects (like in standard models when the ZLB is not binding), i.e. government spending and income tax shocks increase inflation and reduce private absorption. This result is shown analytically and for a calibrated version of the model, including a scenario where the monetary policy rate is temporarily at the ZLB. The analysis thus demonstrates that the ZLB is not particularly 
important for fiscal policy effects when not all interest rates are held fixed at the ZLB. 


\section{References}

Andolfatto, D., and S. Williamson, 2015, Scarcity of Safe Assets, Inflation, and the Policy Trap, Journal of Monetary Economics, forthcoming.

Barro, R., 1981, Output Effects of Government Purchases, Journal of Political Economy 98, 1086-1121.

Baxter M. and B. King, 1993, Fiscal Policy in General Equilibrium, American Economic Review 83, 315-334.

Bech, M.L., E. Klee and V. Stebunovs, 2012, Arbitrage, Liquidity and Exit: the Repo and Federal Funds Markets Before, During, and Emerging from the Financial Crisis, Federal Reserve Board, Finance and Economics Discussion Series, 2012-21.

Bilbiie, F., T. Monacelli, and R. Perotti, 2014, Is Government Spending at the Zero Lower Bound Desirable?, NBER Working Paper No. 20687.

Blanchard, O., and R. Perotti, 2002, An Empirical Characterization of the Dynamic Effects of Changes In Government Spending And Taxes On Output, Quarterly Journal of Economics 117, 1329-1368.

Canova, F. and E. Pappa, 2011, Fiscal Policy, Pricing Frictions and Monetary Accommodation, Economic Policy 26, 555-598.

Carlstrom, C.T., T.S. Fuerst, and M. Paustian, 2014, Fiscal Multipliers Under an Interest Rate Peg of Deterministic Versus Stochastic Duration, Journal of Money, Credit, and Banking 46, 1293-1312.

Caldara, D. and C. Kamps, 2008, What Are the Effects of Fiscal Policy Shocks? A VARbased comparative analysis, ECB Working Paper 877.

Christiano, L., M. Eichenbaum, and C.L. Evans, 2005, Nominal Rigidities and the Dynamic Effects of a Shock to Monetary Policy, Journal of Political Economy 113, $1-45$.

Christiano, L., M. Eichenbaum, and S. Rebelo, 2011, When is the Government Spending Multiplier Large? Journal of Political Economy 119, 78-121.

Cochrane, J.H., 2015, The New-Keynesian Liquidity Trap, University of Chicago Booth School of Business.

Crafts, N. and T.C. Mills, 2013, Fiscal Policy in a Depressed Economy: Was There a Free Lunch in 1930s' Britain?, CEPR Discussion Papers 9273. 
Dupor, B. and R. Li, 2015, The Expected Inflation Channel of Government Spending in the Postwar U.S., European Economic Review 74, 36-56.

Drautzburg, T. and H. Uhlig, 2013, Fiscal Stimulus and Distortionary Taxation, Federal Reserve Bank of Philadelphia, Research Department Working Paper No. 13-46.

Eggertsson, G.B., 2011, What Fiscal Policy Is Effective at Zero Interest Rates? NBER Macroeconomic Annual 2010 25, 59-112.

Enders, Z., G. Müller, and A. Scholl, 2011, How Do Fiscal and Technology Shocks Affect Real Exchange Eates? New Evidence for the United States, Journal of International Economics 83, 53-69.

Erceg C.J. and J. Linde, 2014, Is There a Fiscal Free Lunch in a Liquidity Trap?, Journal of the European Economic Association 12, 73-107.

Fahri, E. and I. Werning, 2013, Fiscal Multipliers: Liquidity Traps and Currency Unions, Harvard University.

Fernández-Villaverde, J., G. Gordon, P. Guerrón-Quintana, and J.F. RubioRamírez, 2012, Nonlinear Adventures at the Zero Lower Bound, University of Pennsylvania.

Galı, J., J.D. Lopez-Salido, and J.Valles, 2007, Understanding the Effects of Government Spending on Consumption, Journal of the European Economic Association 5, $227-270$.

Groth, C. and H. Khan, 2010, Investment Adjustment Costs: An Empirical Assessment, Journal of Money, Credit, and Banking 42, 1469-1494.

Guerrieri, L. and M. Iacoviello, 2014, Occbin: A Toolkit to Solve Models with Occasionally Binding Constraints Easily, Journal of Monetary Economics 70, 22-38.

International Monetary Fund, 2012, What is Libor?, Finance and Development, December 2012 .

Kiley, M.T., 2014, Policy Paradoxes in the New Keynesian Model, Federal Reserve Board, Finance and Economics Discussion Series No. 2014-29.

Linnemann, L. and A. Schabert, 2003, Fiscal Policy in the New Neoclassical Synthesis, Journal of Money, Credit and Banking 35, 911-929.

Mertens K. and M.O. Ravn, 2014, Fiscal Policy in an Expectations Driven Liquidity Trap, Review of Economic Studies, forthcoming. 
Mountford, A. and H. Uhlig, 2009, What Are the Effects of Fiscal Policy Shocks? Journal of Applied Econometrics 24, 960-992.

Ohanian, L., 2011, Discussion of "What Fiscal Policy Is Effective at Zero Interest Rates?" by G. Eggertsson, NBER Macroeconomic Annual 2010 25, 125-137.

Pappa, E., 2009, The Effects of Fiscal Shocks on Employment and the Real Wage, International Economic Review, 50, 217-244.

Perotti, R., 2005, Estimating the Effects of Fiscal Policy in OECD Countries, CEPR Discussion Paper 4842.

Ramey, V.A., 2011, Identifying Government Spending Shocks: It's All in the Timing, Quarterly Journal of Economics 126, 1-50.

Ramey V.A. and S. Zubairy, 2014, Government Spending Multipliers in Good Times and in Bad: Evidence from U.S. Historical Data, University of California, San Diego.

Schabert, A., 2015, Optimal Central Bank Lending, Journal of Economic Theory 157, 485516.

Wieland, J., 2014, Are Negative Supply Shocks Expansionary at the Zero Lower Bound?, University of California, San Diego.

Woodford, M., 2011, Simple Analytics of the Government Expenditure Multiplier, American Economic Journal: Macroeconomics 3, 1-35. 


\section{Appendix}

\section{A Appendix to the empirical analysis}

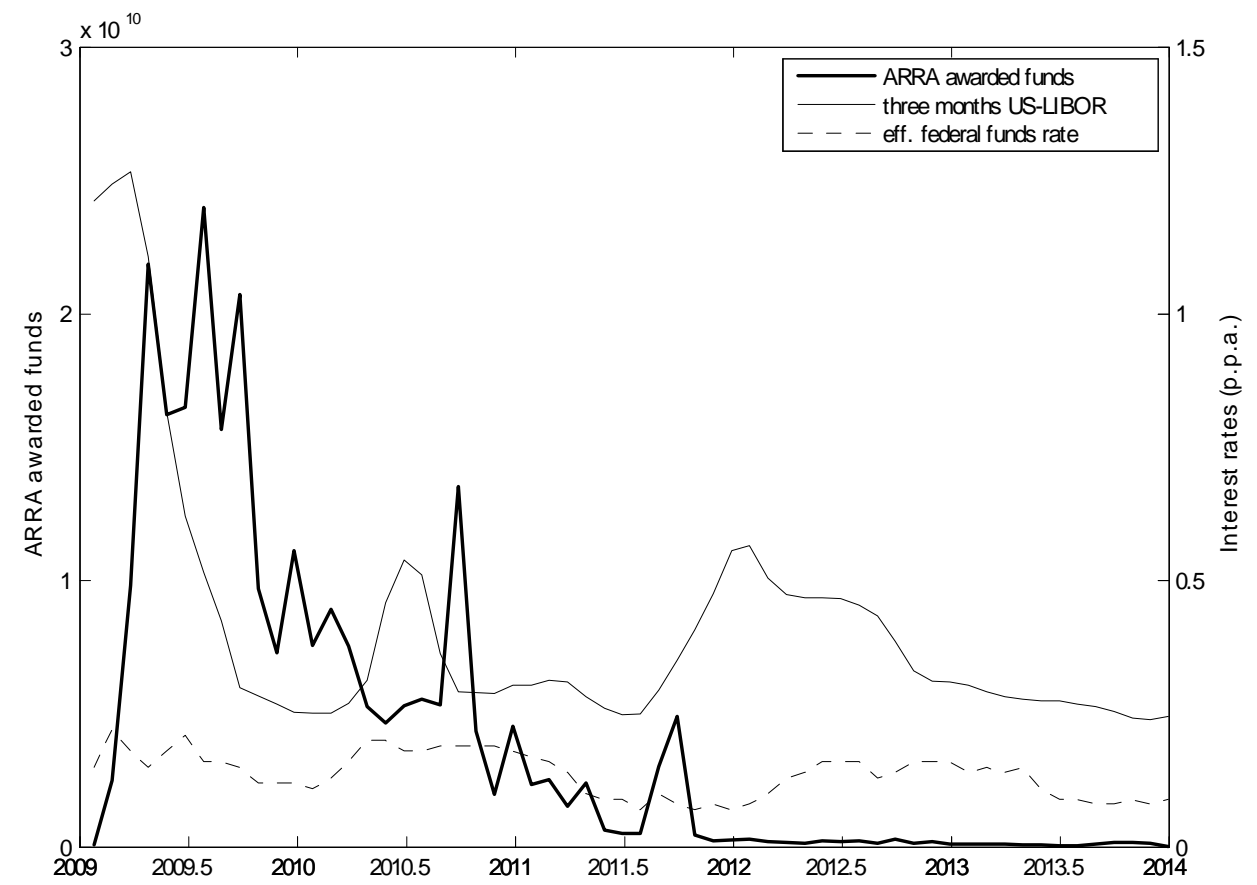

Figure 10: Federal funds rate and 3-month US-LIBOR (monthly and not seasonally adjusted in p.p.a.) (Data sources: FRED database and recovery.gov of the Recovery Accountability and Transparency Board) [Notes: Awarded funds have been summed up by month.]

Real per-capita output is calculated as GDP in billions of current dollars (FRED series ID: GDP) divided by the GDP deflator (GDPDEF) and the civilian noninstitutional population (CNP16OV). The government spending measure is calculated as the sum of Government Consumption Expenditures (A955RC1Q027SBEA) and Gross Government Investment (A782RC1Q027SBEA) divided by the GDP deflator and the civilian noninstitutional population. Private absorption is the sum of personal consumption expenditures (PCE) and gross private domestic investment (GPDI), deflated with the GDP deflator and divided by the civilian noninstitutional population. Output, government spending, and private absorption enter the VAR in logs. The money market spread is the difference between the 3-month LIBOR based on the US dollar (USD3MTD156N) and the (effective) federal funds rate (FEDFUNDS) and enters the VAR in levels. In the VAR using sign restrictions for identification, we further include the primary government deficit which is calculated as the negative sum of net government saving (TGDEF) and government interest payments (A180RC1Q027SBE) divided by the sample mean of GDP. This variable enters the VAR in levels. 

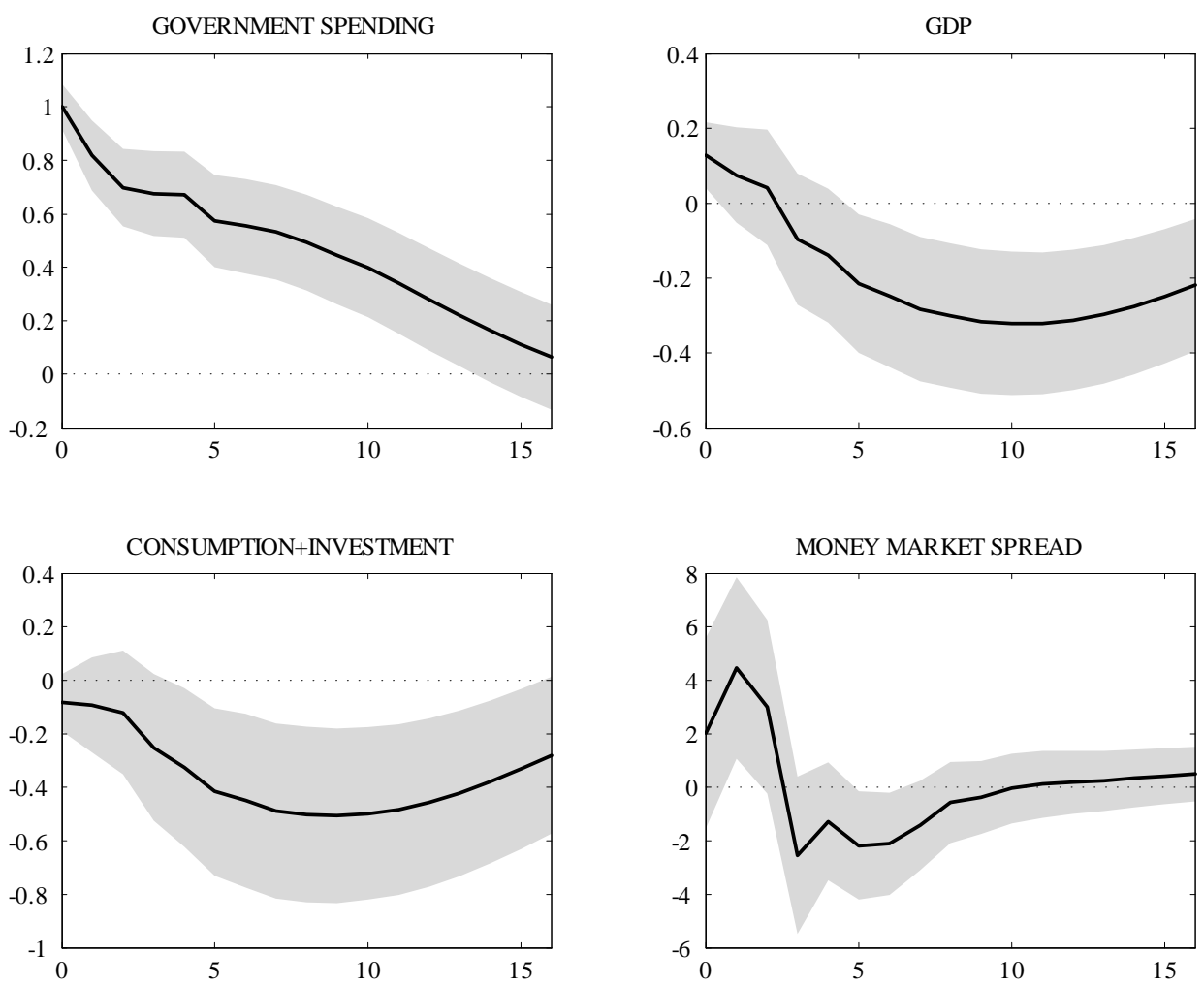

Figure 11: Responses to a government-spending shock, identification: Blanchard and Perotti (2009), sample: 1964.II-2008.II.

\section{B Equilibrium definition}

Definition 1 A rational expectations equilibrium (REE) is a set of sequences $\left\{c_{t}, y_{t}, n_{t}, x_{t}\right.$, $\left.k_{t}, w_{t}, q_{t}, \lambda_{t}, m_{t}^{R}, m_{t}, b_{t}, b_{t}^{T}, m c_{t}, Z_{1, t}, Z_{2, t}, Z_{t}, s_{t}, \pi_{t}, R_{t}^{I S}\right\}_{t=0}^{\infty}$ satisfying

$$
\begin{aligned}
c_{t} & =m_{t}+m_{t}^{R}, \text { if } R_{t}^{I S}>1, \quad \text { or } c_{t} \leq m_{t}+m_{t}^{R}, \text { if } R_{t}^{I S}=1, \\
b_{t-1} /\left(R_{t}^{m} \pi_{t}\right) & =m_{t}-m_{t-1} \pi_{t}^{-1}+m_{t}^{R}, \text { if } R_{t}^{I S}>R_{t}^{m}, \\
\text { or } b_{t-1} /\left(R_{t}^{m} \pi_{t}\right) & \geq m_{t}-m_{t-1} \pi_{t}^{-1}+m_{t}^{R}, \text { if } R_{t}^{I S}=R_{t}^{m}, \\
m_{t}^{R} & =\Omega m_{t}, \\
b_{t} & =b_{t}^{T}-m_{t}, \\
b_{t}^{T} & =\Gamma b_{t-1}^{T} / \pi_{t}, \\
\theta n_{t}^{\sigma n} & =u_{c, t}\left(1-\tau_{t}^{n}\right) w_{t} / R_{t}^{I S}, \\
1 / R_{t}^{I S} & =\beta E_{t}\left[\xi_{t+1} u_{c, t+1} /\left(\xi_{t} u_{c, t} \pi_{t+1}\right)\right], \\
w_{t} & =m c_{t} \alpha n_{t}^{\alpha-1} k_{t-1}^{1-\alpha}, \\
\lambda_{t} & =\beta E_{t}\left[\xi_{t+1} u_{c, t+1} / \pi_{t+1}\right], \\
1 & =q_{t}\left[\Lambda_{t}+\left(x_{t} / x_{t-1}\right) \Lambda_{t}^{\prime}\right]-E_{t} \beta\left[\left(\lambda_{t+1} / \lambda_{t}\right) q_{t+1}\left(x_{t+1} / x_{t}\right)^{2} \Lambda_{t+1}^{\prime}\right], \\
q_{t} & =\beta E_{t}\left[\left(\lambda_{t+1} / \lambda_{t}\right)\left((1-\alpha) m c_{t+1}\left(y_{t+1} / k_{t}\right)+(1-\delta) q_{t+1}\right)\right],
\end{aligned}
$$




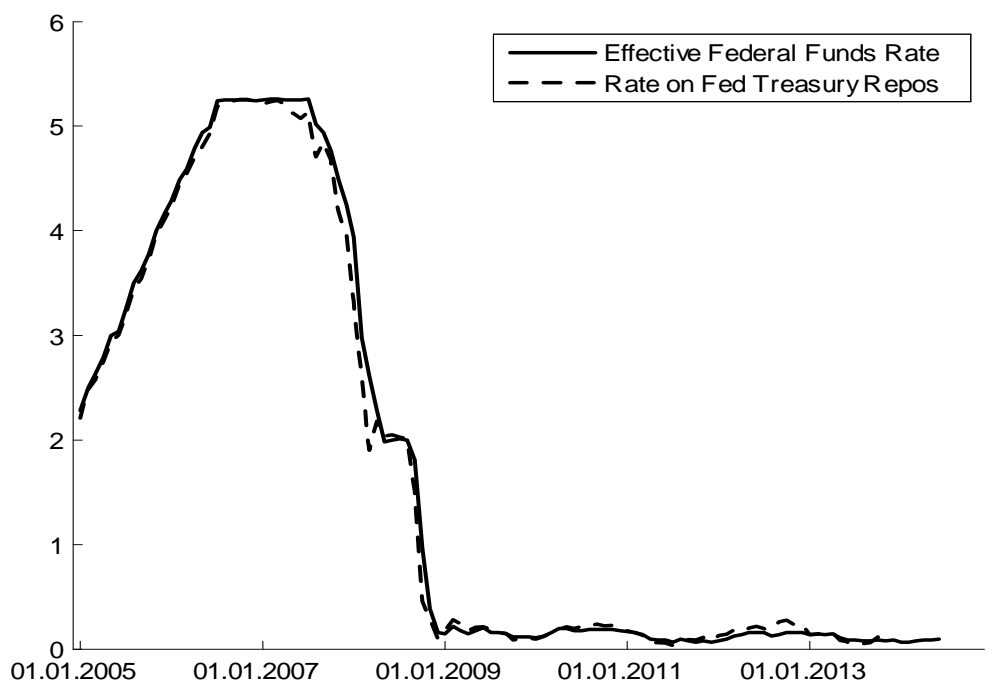

Figure 12: Federal funds rate and treasury repo rate (Data sources: Effective Federal Funds rate: FRED series ID FEDFUNDS; Rate on Fed Treasury Repos: DTCC GCF Repo Index, see http://www.dtcc.com/charts/dtcc-gcf-repo-index.aspx\#download)

$$
\begin{aligned}
Z_{1, t} & =\lambda_{t} y_{t} m c_{t}+\phi \beta E_{t} \pi_{t+1}^{\varepsilon} Z_{1, t+1} \\
Z_{2, t} & =\lambda_{t} y_{t}+\phi \beta E_{t} \pi_{t+1}^{\varepsilon-1} Z_{2, t+1}, \\
Z_{t} & =[\varepsilon /(\varepsilon-1)] Z_{1, t} / Z_{2, t} \\
1 & =(1-\phi) Z_{t}^{1-\varepsilon}+\phi \pi_{t}^{\varepsilon-1} \\
s_{t} & =(1-\phi) Z_{t}^{-\varepsilon}+\phi s_{t-1} \pi_{t}^{\varepsilon} \\
y_{t} & =n_{t}^{\alpha} k_{t-1}^{1-\alpha} / s_{t} \\
y_{t} & =c_{t}+x_{t}+g_{t} \\
k_{t} & =(1-\delta) k_{t-1}+x_{t} \Lambda_{t}
\end{aligned}
$$

(where $\left.u_{c, t}=\left(c_{t}-h c_{t-1}\right)^{-\sigma}, \Lambda_{t}=1-\varsigma \frac{1}{2}\left(x_{t} / x_{t-1}-1\right)^{2}\right)$, the transversality conditions, a monetary policy $\left\{R_{t}^{m} \geq 1\right\}_{t=0}^{\infty}, \Omega>0, \pi \geq \beta$, and a fiscal policy $\left\{g_{t}, \tau_{t}^{n}\right\}_{t=0}^{\infty}, \Gamma \geq 1$, for given sequences $\left\{\xi_{t}\right\}_{t=0}^{\infty}$ and $\left\{\widetilde{y}_{t}\right\}_{t=0}^{\infty}$ (see below) and initial values $M_{-1}>0, B_{-1}>0, B_{-1}^{T}>0$, $k_{-1}>0, x_{-1}>0$, and $s_{-1} \geq 1$.

Given a rational expectations equilibrium as summarized in Definition 1, the equilibrium sequences $\left\{R_{t}, R_{t}^{D}, E_{t} R_{t+1}^{q}, R_{t}^{L}, R_{t}^{A}\right\}_{t=0}^{\infty}$ can be determined by

$$
\begin{aligned}
R_{t} & =E_{t}\left[\xi_{t+1} u_{c, t+1} \pi_{t+1}^{-1}\right] /\left[E_{t}\left(R_{t+1}^{m}\right)^{-1} \xi_{t+1} u_{c, t+1} \pi_{t+1}^{-1}\right], \\
\lambda_{t} / R_{t}^{D} & =\beta E_{t}\left[\left(\xi_{t+1} u_{c, t+1}+(1-\mu) \lambda_{t+1}\right) / \pi_{t+1}\right], \\
1 & =\beta E_{t}\left[\left(R_{t+1}^{q} / \pi_{t+1}\right)\left(\lambda_{t+1} / \lambda_{t}\right)\right] \\
1 / R_{t}^{L} & =E_{t}\left[1 / R_{t+1}^{I S}\right]
\end{aligned}
$$




$$
R_{t}^{A}=R_{t}^{L}
$$

To identify the efficient output level $\widetilde{y}_{t}$, one has to jointly solve for the sequences $\left\{\widetilde{y}_{t}, \widetilde{n}_{t}, \widetilde{c}_{t}, \widetilde{k}_{t}, \widetilde{x}_{t}, \widetilde{q}_{t}\right\}_{t=0}^{\infty}$ satisfying $\theta \widetilde{n}_{t}^{1+\sigma_{n}}=\widetilde{u}_{c t} \alpha \widetilde{y}_{t}, \quad \widetilde{y}_{t}=\widetilde{n}_{t}^{\alpha} \widetilde{k}_{t-1}^{1-\alpha}, \quad \widetilde{y}_{t}=\widetilde{c}_{t}+$ $\widetilde{x}_{t}, \widetilde{k}_{t}=(1-\delta) \widetilde{k}_{t-1}+\widetilde{x}_{t} \Lambda\left(\widetilde{x}_{t} / \widetilde{x}_{t-1}\right), \quad 1=\widetilde{q}_{t}\left[\Lambda\left(\widetilde{x}_{t} / \widetilde{x}_{t-1}\right)+\left(\widetilde{x}_{t} / \widetilde{x}_{t-1}\right) \Lambda^{\prime}\left(\widetilde{x}_{t} / \widetilde{x}_{t-1}\right)\right]-$ $E_{t} \beta\left[\xi_{t+1} \widetilde{u}_{c, t+1}\left(\xi_{t} \widetilde{u}_{c, t}\right)^{-1} \widetilde{q}_{t+1}\left(\widetilde{x}_{t+1} / \widetilde{x}_{t}\right)^{2} \Lambda^{\prime}\left(\widetilde{x}_{t+1} / \widetilde{x}_{t}\right)\right]$, and $\widetilde{q}_{t}=\beta E_{t}\left[\xi_{t+1} \widetilde{u}_{c, t+1}\left(\xi_{t} \widetilde{u}_{c, t}\right)^{-1}((1-\right.$ $\left.\left.\alpha)\left(\widetilde{y}_{t+1} / \widetilde{k}_{t}\right)+(1-\delta) \widetilde{q}_{t+1}\right)\right]$, where $\widetilde{u}_{c, t}=\left(\widetilde{c}_{t}-h \widetilde{c}_{t-1}\right)^{-\sigma}$ given $\left\{\xi_{t}\right\}_{t=0}^{\infty}, \widetilde{x}_{-1}>0$, and $\widetilde{k}_{-1}>0$.

If the money supply constraint (8) is not binding, which would be the case when the policy rate equals the marginal rate of intertemporal substitution, $R_{t}^{m}=R_{t}^{I S}$ (see 17), the model as given in Definition 1 can be reduced to a conventional sticky price model with capital accumulation and a cash-in-advance constraint, where Ricardian equivalence holds and money holdings can separately be determined by (30) and (32) if $R_{t}^{I S}>1$.

Definition 2 A rational expectations equilibrium (REE) under a non-binding money supply constraint (8) is a set of sequences $\left\{c_{t}, y_{t}, n_{t}, x_{t}, k_{t}, w_{t}, q_{t}, \lambda_{t}, m c_{t}, Z_{1, t}, Z_{2, t}, Z_{t}, s_{t}, \pi_{t}\right.$, $\left.R_{t}^{I S}\right\}_{t=0}^{\infty}$ satisfying $R_{t}^{I S}=R_{t}^{m}$, (35)-(48), the transversality conditions, a monetary policy $\left\{R_{t}^{m} \geq 1\right\}_{t=0}^{\infty}, \pi \geq \beta$, and a fiscal policy $\left\{g_{t}, \tau_{t}^{n}\right\}_{t=0}^{\infty}$, for given sequences $\left\{\xi_{t}\right\}_{t=0}^{\infty}$ and $\left\{\widetilde{y}_{t}\right\}_{t=0}^{\infty}$ and initial values $k_{-1}>0, x_{-1}>0$, and $s_{-1} \geq 1$.

Note that the model summarized in Definition 2 is identical to a textbook New Keynesian model with capital accumulation (and without the cash-credit good friction) when the policy rate $R_{t}^{m}$ and, thus, $R_{t}^{I S}$ are at the zero lower bound, such that the cash-in-advance constraint becomes irrelevant.

\section{Appendix to the simplified version}

In this Appendix, we simplify the model by restricting the parameter values to $h=\rho_{R, y, g, \tau}=$ $0, \alpha=\pi=\Gamma=1$, and $\Omega \rightarrow \infty$. We further assume that the mean policy rate and the inflation target are set at $R^{m}<\pi / \beta$, such that the money supply constraint (8) is binding in the steady state (see 17) and in its neighborhood. Shocks are assumed to be sufficiently small to stay in the neighborhood of this steady state and to ensure that the policy rate does not hit the ZLB.

Definition 3 For $h=\rho_{R, y, g, \tau}=0, \alpha=\pi=\Gamma=1, R^{m}<\pi / \beta, \Omega \rightarrow \infty$, and a slack ZLB, a $R E E$ is a set of sequences $\left\{c_{t}, y_{t}, n_{t}, w_{t}, m_{t}^{R}, b_{t}, m c_{t}, Z_{1, t}, Z_{2, t}, Z_{t}, s_{t}, \pi_{t}, R_{t}^{I S}\right\}_{t=0}^{\infty}$ satisfying (35)-(36), (41)-(45), $c_{t}=m_{t}^{R}, b_{t-1} /\left(R_{t}^{m} \pi_{t}\right)=m_{t}^{R}, w_{t}=m c_{t}, y_{t}=n_{t} / s_{t}, b_{t}=b_{t-1} / \pi_{t}$, $y_{t}=c_{t}+g_{t}$, and the transversality conditions, a monetary policy $R_{t}^{m} / R^{m}=\left(\pi_{t} / \pi\right)^{\rho_{\pi}}$, and a fiscal policy $\left\{g_{t}, \tau_{t}^{n}\right\}_{t=0}^{\infty}$, for given sequences $\left\{\xi_{t}\right\}_{t=0}^{\infty}$ and $\left\{\widetilde{y}_{t}\right\}_{t=0}^{\infty}$ and initial values $B_{-1}>0$, and $s_{-1} \geq 1$.

We apply a log-linear approximation of the equilibrium conditions given in Definition 3, in the neighborhood of a steady state (with $R^{m}<\pi / \beta$ ). Then, (41)-(43) are well-known to 
reduce to $\widehat{\pi}_{t}=\beta E_{t} \widehat{\pi}_{t+1}+\chi \widehat{m c}_{t}$, where $\chi=(1-\phi)(1-\beta \phi) / \phi$, while $Z_{1, t}, Z_{2, t}, Z_{t}$, and $s_{t}$ become irrelevant. Further substituting out $\widehat{y}_{t}, \widehat{n}_{t}, \widehat{m}_{t}^{R}, \widehat{m c}_{t}$, and $\widehat{w}_{t}$, the log-linearized version of the equilibrium conditions can be reduced to a system in $\widehat{\pi}_{t}, \widehat{c}_{t}$, and $\widehat{b}_{t}$ satisfying,

$$
\begin{aligned}
\delta_{1} E_{t} \widehat{\pi}_{t+1}+\delta_{3} \widehat{b}_{t}+\delta_{2} \widehat{c}_{t} & =\widehat{\pi}_{t}-\left(\delta_{\xi} \widehat{\xi}_{t}+\delta_{g} \widehat{g}_{t}+\delta_{\tau} \widehat{\tau}_{t}^{n}\right), \\
\widehat{c}_{t} & =\widehat{b}_{t-1}-\left(1+\rho_{\pi}\right) \widehat{\pi}_{t}, \\
\widehat{b}_{t} & =\widehat{b}_{t-1}-\widehat{\pi}_{t},
\end{aligned}
$$

where $\delta_{1}=\left(\beta+\chi(1-\sigma)-\chi \sigma \rho_{\pi}\right) \gtreqless 0, \delta_{2}=\chi \sigma_{n} c /(c+g)>0, \delta_{3}=\chi \sigma>0, \delta_{\xi}=$ $\chi\left(1-\rho_{\xi}\right)>0, \delta_{g}=\chi \sigma_{n} g /(c+g)>0$ and $\delta_{\tau}=\chi \frac{\tau^{n}}{1-\tau^{n}}>0$, while one can separately solve for $\widehat{R}_{t}^{m}$ and $\widehat{R}_{t}^{I S}$ with $\widehat{R}_{t}^{m}=\rho_{\pi} \widehat{\pi}_{t}$ and $\widehat{R}_{t}^{I S}=\sigma E_{t} \widehat{c}_{t+1}-\sigma \widehat{c}_{t}+E_{t} \widehat{\pi}_{t+1}+\widehat{\xi}_{t}-E_{t} \widehat{\xi}_{t+1}$.

Proof of proposition 1. To establish the claims made in the proposition, we further simplify the system (54)-(56) by eliminating $\widehat{c}_{t}$ with (55) in (54)

$$
\delta_{1} E_{t} \widehat{\pi}_{t+1}+\left(\delta_{3}+\delta_{2}\right) \widehat{b}_{t}=\left(1+\delta_{2} \rho_{\pi}\right) \widehat{\pi}_{t}-\left(\delta_{\xi} \widehat{\xi}_{t}+\delta_{g} \widehat{g}_{t}+\delta_{\tau} \widehat{\tau}_{t}^{n}\right)
$$

and rewriting (56) and (57) in matrix form

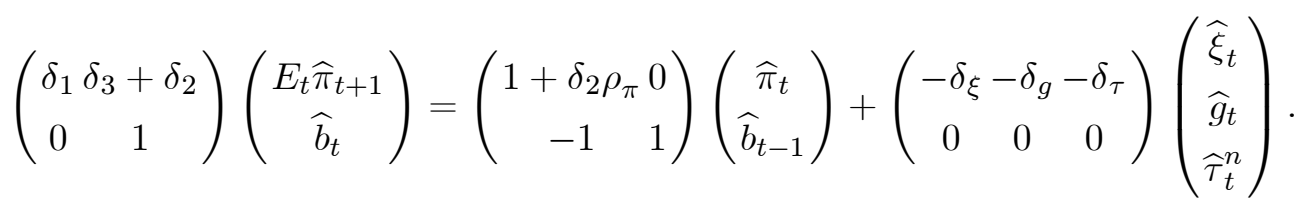

The characteristic polynomial of

$$
\mathbf{A}=\left(\begin{array}{cc}
\delta_{1} \delta_{3}+\delta_{2} \\
0 & 1
\end{array}\right)^{-1}\left(\begin{array}{cc}
1+\delta_{2} \rho_{\pi} & 0 \\
-1 & 1
\end{array}\right)
$$

is given by

$$
F(X)=X^{2}-\frac{\delta_{1}+\delta_{2}+\delta_{3}+\rho_{\pi} \delta_{2}+1}{\delta_{1}} X+\frac{\rho_{\pi} \delta_{2}+1}{\delta_{1}} .
$$

Given that there is one backward-looking variable and one forward-looking variable, stability and uniqueness require $F(X)$ to be characterized by one stable and one unstable root. At $X=0$, the sign of $F(X)$ equals the sign of $\delta_{1}, F(0)=\left(\rho_{\pi} \delta_{2}+1\right) / \delta_{1}$, while $F(X)$ exhibits the opposite sign at $X=1: F(1)=-\frac{1}{\delta_{1}}\left(\delta_{2}+\delta_{3}\right)$. Consider first the case where $\delta_{1}=$ $\beta+\chi(1-\sigma)-\chi \sigma \rho_{\pi}>0 \Leftrightarrow$

$$
\rho_{\pi}<\frac{\beta}{\sigma \chi}+\frac{1-\sigma}{\sigma} .
$$

Given that $\sigma \geq 1$ and $\beta<1$, we know that $\delta_{1}$ is then strictly smaller than one. Hence, $F(1)<0$ and $F(0)>1$, which implies that exactly one root is unstable and the stable root is strictly positive. Now consider the second case where $\delta_{1}=\beta+\chi(1-\sigma)-\chi \sigma \rho_{\pi}<0 \Leftrightarrow$ $\rho_{\pi}>\frac{\beta+\chi(1-\sigma)}{\chi \sigma}$, such that $F(1)>0$ and $F(0)<0$. We then know that there is at least one stable root between zero and one. To establish a condition which ensures that there is exactly 
one stable root, we further use $F(-1)=\left[2\left(1+\delta_{1}\right)+\delta_{3}+\left(2 \rho_{\pi}+1\right) \delta_{2}\right] / \delta_{1}$. Rewriting the numerator with $\delta_{1}=\beta+\chi(1-\sigma)-\chi \sigma \rho_{\pi}, \delta_{2}=\chi \sigma_{n} c /(c+g)$ and $\delta_{3}=\chi \sigma$, the condition

$$
2\left(1+\beta+\chi(1-\sigma)-\chi \sigma \rho_{\pi}\right)+\delta_{3}+\left(2 \rho_{\pi}+1\right) \delta_{2}>0
$$

ensures that $F(0)$ and $F(-1)$ exhibit the same sign implying that there is no stable root between zero and minus one. We now use that (60) holds, if but not only if

$$
\rho_{\pi} \leq \frac{1+\beta}{\chi \sigma}+\frac{1-\sigma}{\sigma}
$$

where the RHS of (61) is strictly larger than the RHS of (59). Hence, (61) is sufficient for local equilibrium determinacy, which establishes the claim made in the proposition.

Proof of proposition 2. Consider the set of equilibrium conditions (54)-(56). We aim at identifying the impact responses to fiscal policy shocks. For this, we assume that (61) is satisfied, which ensures existence and uniqueness of a locally stable solution. We therefore apply the following solution form for the system (54)-(56)

$$
\begin{aligned}
\widehat{\pi}_{t} & =\gamma_{\pi b} \widehat{b}_{t-1}+\gamma_{\pi g} \widehat{g}_{t}+\gamma_{\pi \tau} \widehat{\tau}_{t}+\gamma_{\pi \xi} \widehat{\xi}_{t}, \\
\widehat{b}_{t} & =\gamma_{b} \widehat{b}_{t-1}+\gamma_{b g} \widehat{g}_{t}+\gamma_{b \tau} \widehat{\tau}_{t}+\gamma_{b \xi} \widehat{\xi}_{t}, \\
\widehat{c}_{t} & =\gamma_{c b} \widehat{b}_{t-1}+\gamma_{c g} \widehat{g}_{t}+\gamma_{c \tau} \widehat{\tau}_{t}+\gamma_{c \xi} \widehat{\xi}_{t} .
\end{aligned}
$$

In what follows, we identify the undetermined coefficients for in (62)-(64) that are associated with fiscal policy shocks. Substituting out the endogenous variables in (54)-(56) with generic solutions in (62)-(64), leads to the following conditions for $\gamma_{\pi b}, \gamma_{c b}, \gamma_{\pi b}, \gamma_{c g}, \gamma_{\pi g}, \gamma_{b g}, \gamma_{c \tau}$, $\gamma_{\pi \tau}$, and $\gamma_{b \tau}$ :

$$
\begin{gathered}
\gamma_{\pi b}=\delta_{1} \gamma_{\pi b} \gamma_{b}+\delta_{3} \gamma_{b}+\delta_{2} \gamma_{c b}, 1=\left(1+\rho_{\pi}\right) \gamma_{\pi b}+\gamma_{c b}, 1=\gamma_{b}+\gamma_{\pi b}, \\
-\delta_{2} \gamma_{c g}=\left(\delta_{1} \gamma_{\pi b}+\delta_{3}\right) \gamma_{b g}-\gamma_{\pi g}+\delta_{g},-\gamma_{c g}=\left(1+\rho_{\pi}\right) \gamma_{\pi g}, \gamma_{b g}=-\gamma_{\pi g}, \\
-\delta_{2} \gamma_{c \tau}=\left(\delta_{1} \gamma_{\pi b}+\delta_{3}\right) \gamma_{b \tau}-\gamma_{\pi \tau}+\delta_{\tau},-\gamma_{c \tau}=\left(1+\rho_{\pi}\right) \gamma_{\pi \tau}, \gamma_{b \tau}=-\gamma_{\pi \tau} .
\end{gathered}
$$

Using the three conditions in (65) and substituting out $\gamma_{\pi b}$ with $\gamma_{\pi b}=1-\gamma_{b}$, gives $0=$ $\left(\delta_{1} \gamma_{b}-1\right)\left(1-\gamma_{b}\right)+\delta_{3} \gamma_{b}+\delta_{2} \gamma_{c b}, 1=\left(1+\rho_{\pi}\right)\left(1-\gamma_{b}\right)+\gamma_{c b}$, and eliminating $\gamma_{c b}$ with $\gamma_{c b}=$ $1-\left(1+\rho_{\pi}\right)\left(1-\gamma_{b}\right)$, leads to $0=\left(\delta_{1} \gamma_{b}-1\right)\left(1-\gamma_{b}\right)+\delta_{3} \gamma_{b}+\delta_{2}\left(1-\left(1+\rho_{\pi}\right)\left(1-\gamma_{b}\right)\right)$, which is a quadratic equation in $\gamma_{b}$,

$$
\gamma_{b}^{2}-\left(\delta_{1}+\delta_{3}+\delta_{2}\left(\rho_{\pi}+1\right)+1\right) \gamma_{b} \delta_{1}^{-1}+\left(\rho_{\pi} \delta_{2}+1\right) \delta_{1}^{-1}=0 .
$$

Note that the polynomial in (68) is the characteristic polynomial of $\mathbf{A}$ (see 58). Hence, under (61) there exists exactly one stable and positive solution (see proof of proposition 1), which is assigned to $\gamma_{b} \in(0,1)$. We can then use $\gamma_{c b}=1-\left(1+\rho_{\pi}\right)\left(1-\gamma_{b}\right)$ and $\gamma_{\pi b}=1-\gamma_{b}>0$, to 
identify the effects of government expenditure shocks with the three conditions in (66). The latter imply that the impact responses of inflation and consumption exhibit different signs, $\gamma_{c g}=-\left(1+\rho_{\pi}\right) \gamma_{\pi g}$, and after eliminating $\gamma_{b g}$ with $\gamma_{b g}=\left(1+\rho_{\pi}\right)^{-1} \gamma_{c g}$, lead to

$$
\gamma_{c g}=-\frac{\left(1+\rho_{\pi}\right) \delta_{g}}{\delta_{1} \gamma_{\pi b}+\delta_{3}+1+\left(1+\rho_{\pi}\right) \delta_{2}} .
$$

Using $\delta_{1}=\beta+\chi(1-\sigma)-\chi \sigma \rho_{\pi}, \delta_{2}=\chi \sigma_{n} c /(c+g)>0$, and $\delta_{3}=\chi \sigma>0$, the term on the RHS of (69) can be rewritten in a way that reveals an unambiguous sign of $\gamma_{c g}$,

$$
\gamma_{c g}=-\frac{\left(1+\rho_{\pi}\right) \delta_{g}}{(\beta+\chi(1-\sigma)-\chi \sigma \rho) \gamma_{\pi b}+\chi \sigma+1+\left(1+\rho_{\pi}\right) \delta_{2}}<0,
$$

for which we used $\delta_{2}>0$ and $\beta+\chi(1-\sigma)-\chi \sigma \rho_{\pi}+1>0$ (see 61), ensuring a strictly positive denominator, and $\delta_{g}>0$. Now consider the three conditions in (67) to identify the tax effects and substitute out $\gamma_{b \tau}$ with $\gamma_{b \tau}=-\gamma_{\pi \tau}$ and $\gamma_{\pi \tau}$ with $\gamma_{\pi \tau}=-\left(1+\rho_{\pi}\right)^{-1} \gamma_{c \tau}$, which leads to

$$
\gamma_{c \tau}=-\frac{\left(1+\rho_{\pi}\right) \delta_{\tau}}{\delta_{1} \gamma_{\pi b}+\delta_{3}+1+\left(1+\rho_{\pi}\right) \delta_{2}} .
$$

Given that the denominator on the RHS of (70) is identical to the one of $\gamma_{c g}$, we can conclude that consumption falls on impact in response to higher government spending and higher taxes, while inflation increases as $\gamma_{\pi g}=-\gamma_{c g}\left(1+\rho_{\pi}\right)^{-1}>0$ and $\gamma_{\pi \tau}=-\left(1+\rho_{\pi}\right)^{-1} \gamma_{c \tau}>0$.

Using these results, we can immediately identify the response of the nominal marginal rate of intertemporal substitution, which in log-linearized form is given by $\widehat{R}_{t}^{I S}=\sigma E_{t} \widehat{c}_{t+1}-$ $\sigma \widehat{c}_{t}+E_{t} \widehat{\pi}_{t+1}+\widehat{\xi}_{t}-E_{t} \widehat{\xi}_{t+1}$. Applying the solution (62)-(64), we get the following expressions for the impact effects of fiscal policy shocks

$$
\begin{aligned}
\partial \widehat{R}_{t}^{I S} / \partial \widehat{g}_{t} & =-\sigma \gamma_{c g}+\left(\sigma \gamma_{c b}+\gamma_{\pi b}\right) \gamma_{b g}, \\
\partial \widehat{R}_{t}^{I S} / \partial \widehat{\tau}_{t} & =-\sigma \gamma_{c \tau}+\left(\sigma \gamma_{c b}+\gamma_{\pi b}\right) \gamma_{b \tau} .
\end{aligned}
$$

Using $\gamma_{\pi b}=1-\gamma_{b}, \gamma_{c b}=1-\left(1+\rho_{\pi}\right)\left(1-\gamma_{b}\right), \gamma_{\pi g}=-\frac{\gamma_{c g}}{1+\rho_{\pi}}, \gamma_{b g}=\frac{\gamma_{c g}}{1+\rho_{\pi}}, \gamma_{\pi \tau}=-\frac{\gamma_{c \tau}}{1+\rho_{\pi}}$, and $\gamma_{b \tau}=\frac{\gamma_{c \tau}}{1+\rho_{\pi}}$, (71) and (72) can be rewritten as

$$
\begin{aligned}
\partial \widehat{R}_{t}^{I S} / \partial \widehat{g}_{t} & =\left[\sigma \rho_{\pi}\left(1+\left(1-\gamma_{b}\right)\right)+(\sigma-1)\left(1-\gamma_{b}\right)\right] \gamma_{\pi g} \geq 0 \\
\partial \widehat{R}_{t}^{I S} / \partial \widehat{\tau}_{t} & =\left[\sigma \rho_{\pi}\left(1+\left(1-\gamma_{b}\right)\right)+(\sigma-1)\left(1-\gamma_{b}\right)\right] \gamma_{\pi g} \geq 0
\end{aligned}
$$

indicating positive impact effects of an increase in $g_{t}$ or $\tau_{t}$ on $R_{t}^{I S}$. Using (73)-(74), $\widehat{R}_{t}^{m}=$ $\rho_{\pi} \widehat{\pi}_{t}, \gamma_{\pi g}=-\gamma_{c g}\left(1+\rho_{\pi}\right)^{-1}>0$ and $\gamma_{\pi \tau}=-\left(1+\rho_{\pi}\right)^{-1} \gamma_{c \tau}>0$, further shows that the spread $\widehat{R}_{t}^{I S}-\widehat{R}_{t}^{m}$ also increases in response to positive $g_{t}$ or $\tau_{t}$ shocks:

$$
\begin{aligned}
& \partial\left(\widehat{R}_{t}^{I S}-\widehat{R}_{t}^{m}\right) / \partial \widehat{g}_{t}=\left[\sigma \rho_{\pi}\left(1-\gamma_{b}\right)+(\sigma-1)\left(1-\gamma_{b}+\rho_{\pi}\right)\right] \gamma_{\pi g} \geq 0, \\
& \partial\left(\widehat{R}_{t}^{I S}-\widehat{R}_{t}^{m}\right) / \partial \widehat{\tau}_{t}=\left[\sigma \rho_{\pi}\left(1-\gamma_{b}\right)+(\sigma-1)\left(1-\gamma_{b}+\rho_{\pi}\right)\right] \gamma_{\pi g} \geq 0,
\end{aligned}
$$


which establishes the claims made in the proposition.

\section{Additional model evaluations}
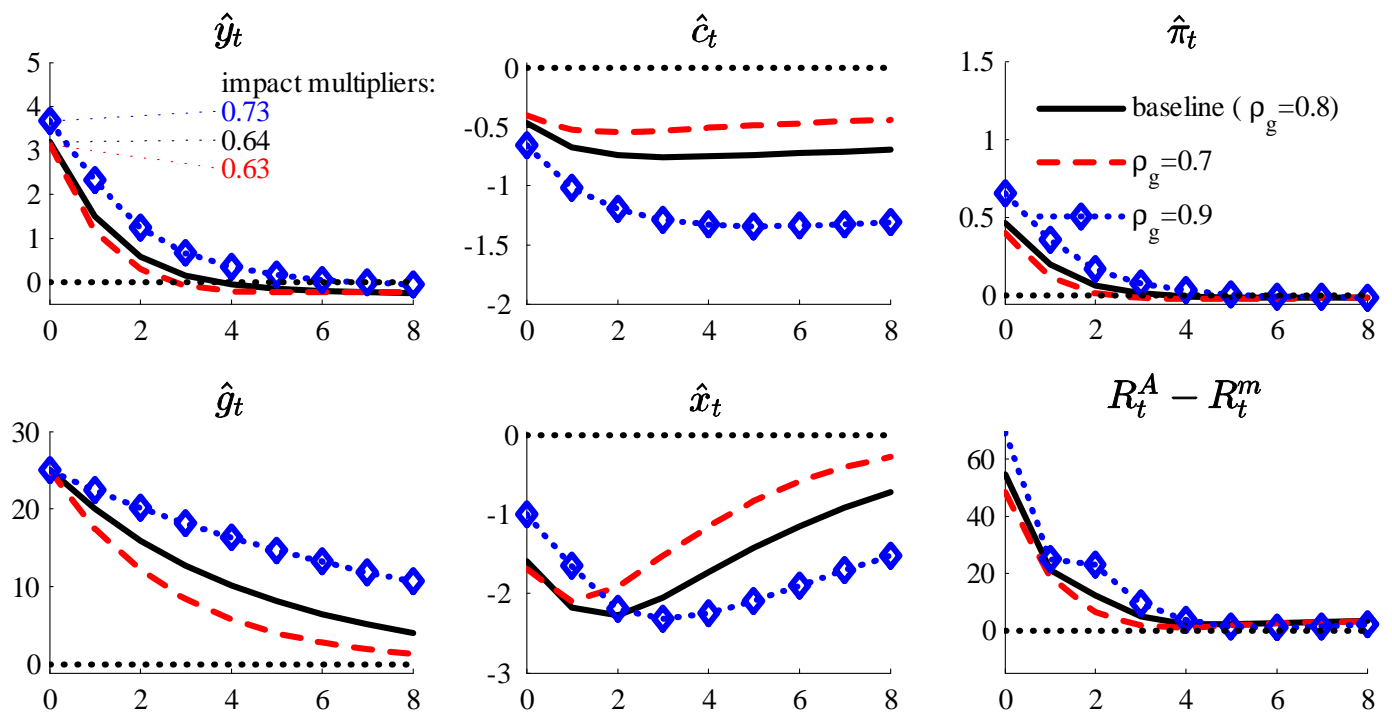

Net effect of a government spending shock for different degrees of autocorrelation
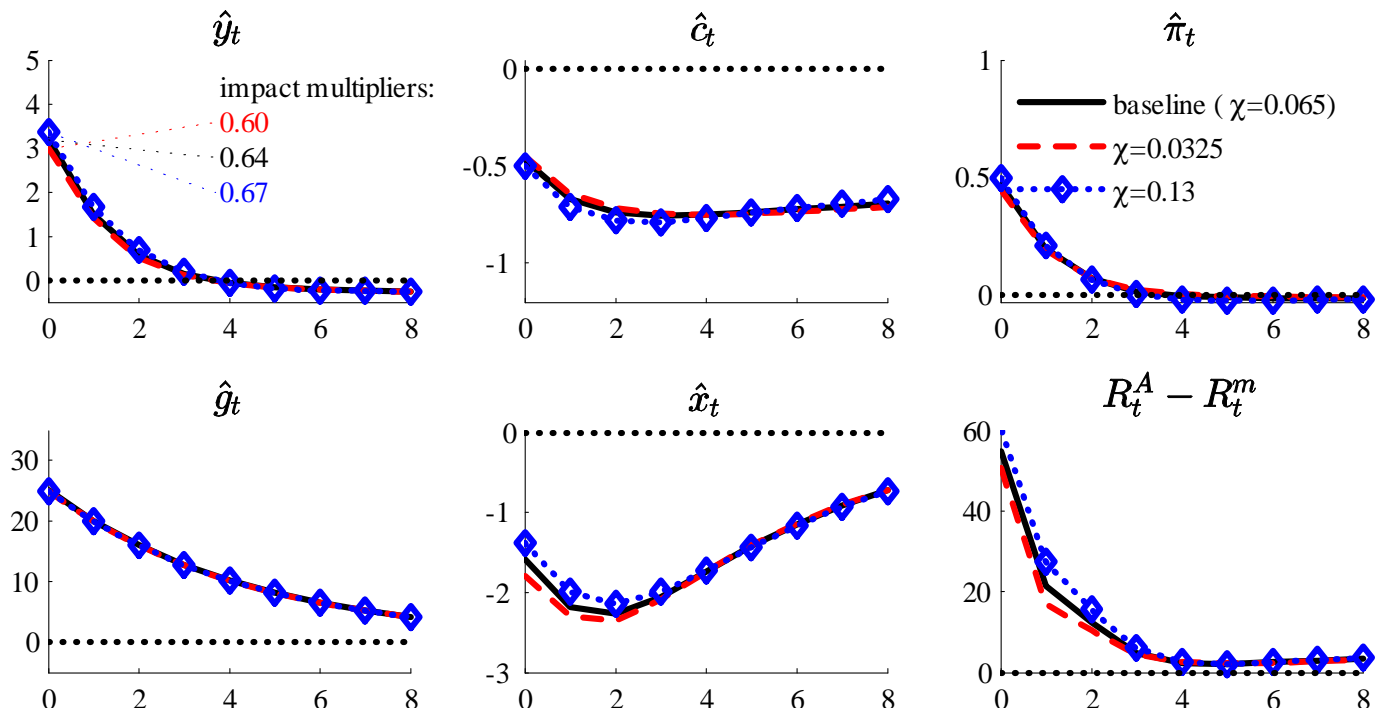

Net effect of government spending shock for different investment adjustment costs 